\title{
Effect of microstructure of a NiCoCrAIY coating fabricated by high-velocity air fuel on the isothermal oxidation
}

DOI:

10.1016/j.corsci.2019.108126

\section{Document Version}

Accepted author manuscript

Link to publication record in Manchester Research Explorer

\section{Citation for published version (APA):}

Lu, J., Zhang, H., Chen, Y., Zhao, X., Guo, F., \& Xiao, P. (2019). Effect of microstructure of a NiCoCrAlY coating fabricated by high-velocity air fuel on the isothermal oxidation. Corrosion Science, 159.

https://doi.org/10.1016/j.corsci.2019.108126

\section{Published in:}

Corrosion Science

\section{Citing this paper}

Please note that where the full-text provided on Manchester Research Explorer is the Author Accepted Manuscript or Proof version this may differ from the final Published version. If citing, it is advised that you check and use the publisher's definitive version.

\section{General rights}

Copyright and moral rights for the publications made accessible in the Research Explorer are retained by the authors and/or other copyright owners and it is a condition of accessing publications that users recognise and abide by the legal requirements associated with these rights.

\section{Takedown policy}

If you believe that this document breaches copyright please refer to the University of Manchester's Takedown Procedures [http://man.ac.uk/04Y6Bo] or contact uml.scholarlycommunications@manchester.ac.uk providing relevant details, so we can investigate your claim.

\section{OPEN ACCESS}




\title{
Effect of microstructure of a NiCoCrAIY coating fabricated by high-velocity air fuel on the isothermal oxidation
}

Jie Lu ${ }^{a}$, Han Zhang ${ }^{a}$, Ying Chen ${ }^{b}$, Han Zhang ${ }^{a}$, Xiaofeng Zhao ${ }^{a, *}$, Fangwei Guo $^{a}$, Ping Xiao ${ }^{c}$

${ }^{a}$ Shanghai Key Laboratory of Advanced High-Temperature Materials and Precision Forming, School of Materials Science and Engineering, Shanghai Jiao Tong University, Shanghai, 200240, China

${ }^{b}$ OxMet Technologies, Begbroke Science Park, Oxfordshire, OX5 1PF, United Kingdom

${ }^{c}$ School of Materials, The University of Manchester, MSS Tower, Manchester M13 9PL, United Kingdom

\begin{abstract}
The effect of grain size, dislocations and porosity of a NiCoCrAlY coating fabricated by high-velocity air fuel on the isothermal oxidation behavior is studied. To understand this effect, the microstructure of coating, the chemistry and microstructure of thermally grown oxides (TGO), the phase transformation of alumina, the oxidation rate, and the TGO stress are investigated. It is demonstrated in this study that the oxidation and spallation resistance of TGO are predominantly determined by the porosity rather than grain size and dislocation for the long term oxidation, although the fine $\gamma$-grains and dislocation can facilitate the earlier establishment of $\alpha-\mathrm{Al}_{2} \mathrm{O}_{3}$ scale.
\end{abstract}

$\underline{\text { Keywords: NiCoCrAlY; Grain size; Dislocation; Porosity; Oxidation. }}$

* Corresponding author: Xiaofeng Zhao

Tel./fax:+86-21-54742561.

(xiaofengzhao@sjtu.edu.cn) 


\section{Introduction}

MCrAlY ( $\mathrm{M}=\mathrm{Ni}$, Co or both) coatings are widely employed as bond coat materials for thermal barrier coatings, or protective coatings for many demanded applications (e.g. aeroengine and power generation gas turbines) due to its exceptional oxidation and corrosion resistance at elevated temperature[1-4]. The oxidation resistance of these coatings rely on the capability to develop a mechanically stable, slow growing, adherent alumina-based thermally grown oxides (TGO) over the coating surface upon exposure to high temperatures[5,6].

The MCrAlY coatings are typically fabricated by atmospheric plasma spray (APS), low pressure plasma spray (LPPS) and vacuum plasma spraying (VPS). For the APS sprayed MCrAlY coating, the intrinsic imperfections (e.g. pores and internal oxides) in the underlying coating always enhance the depletion of aluminum. When the content of aluminum is lower than the critical level of alumina nucleation, the spinel (e.g. $\left.(\mathrm{Co}, \mathrm{Ni})(\mathrm{Cr}, \mathrm{Al})_{2} \mathrm{O}_{4}\right)$ and breakaway oxides will develop in the TGO and thus induce failure of coatings [7-11]. The industrial applications are limited for the MCrAlY coating fabricated by LPPS and VPS due to the high cost, although the coating shows a better oxidation resistance performance in comparison to APS coating [7]. To lower the cost and fabricate a high-performance MCrAlY coating, high-velocity oxygen fuel (HVOF) technique is employed to fabricate the MCrAlY coatings. The oxidation behavior of HVOF-sprayed MCrAlY coatings has been extensively studied in the previous investigations [12-14]. The recently developed HVAF technique has attracted constantly increased attention as a potential replacement of HVOF [15]. The in-situ oxidation can be significantly reduced during spraying by replacing pure oxygen in HVOF with air in the HVAF process, except for the lower cost $[16,17]$. The lower inflight particle temperature, higher particle velocity in the flame, and greater control of the process compared with HVOF can lead to the minimal particle phase transformation and higher coating densification [17]. Thus the HVAF technique is likely to be more appropriate for fabricating high-performance MCrAlY coatings with both lower porosity and lower oxygen content compared with the HVOF. At present, only a few 
investigations to report the oxidation behavior of HVAF-sprayed MCrAlY coatings. It is reported by Luo et.al [6] that the HVAF-sprayed NiCoCrAlY coating shows a better oxidation resistance at $1150{ }^{\circ} \mathrm{C}$ than APS, which is attributed to the dense microstructure of coating. Zhang et.al [18] investigates the effect of surface treatment on the growth of transient alumina in the initial oxidation stage at $1000{ }^{\circ} \mathrm{C}$ for the HVAF-sprayed NiCoCrAlY coating. However, the effect of intrinsic microstructure (grain size and porosity) on the oxidation behavior of HVAF-sprayed MCrAlY coatings remains unclear. Understanding on this point could help develop a high-performance MCrAlY coating.

In the present work, the objective is to provide detailed characterization and mechanistic understanding of the isothermal oxidation of HVAF-sprayed NiCoCrAlY coating, with a focus on the effect of the microstructure (grain size and porosity) of the coatings. For comparison, other two types of HVAF-sprayed coatings with larger grain size and lower porosity prepared by subsequent vacuum heat treatment and spark plasma sintering treatment are also studied. The isothermal oxidation test was carried out at $1150{ }^{\circ} \mathrm{C}$ in laboratory air. Both microstructure, phase transformation of alumina scale, oxidation rate, the residual stress, and the failure mechanism of TGO for these coatings are systematically investigated.

\section{Experimental procedure}

\subsection{Material and sample preparation}

Nickel-based Hastelloy® X polycrystalline superalloy was used as the substrate material, which was grit blasted and ultrasonically cleaned in acetone prior to deposition. . The M3 ${ }^{\mathrm{TM}}-\mathrm{HVAF}$ spraying system (Uniquecoat, Oilville, VA, USA) was employed to fabricate the NiCoCrAlY coating. Three types of coatings were designed, namely the $\boldsymbol{H} \boldsymbol{V A F}$ coating (prepared by HVAF), $\boldsymbol{H} \boldsymbol{V A F}-\boldsymbol{V}$ coating (prepared by HVAF and followed by $4 \mathrm{~h}$ vacuum heat treatment at $1100{ }^{\circ} \mathrm{C}$ in vacuum $\left.\left(\leqslant 10^{-5} \mathrm{~Pa}\right)\right)$ and $\boldsymbol{H V A F - S ~ c o a t i n g ~ ( p r e p a r e d ~ b y ~ H V A F ~ a n d ~ f o l l o w e d ~ b y ~ s p a r k ~ p l a s m a ~ s i n t e r i n g ~ t r e a t m e n t ~}$ 
at $1050{ }^{\circ} \mathrm{C}$ for $10 \mathrm{~min}$ under a pressure of $50 \mathrm{MPa}$ in vacuum $\left(\leqslant 10^{-5} \mathrm{~Pa}\right)$, with a heating rate of $\left.100{ }^{\circ} \mathrm{C} / \mathrm{min}\right)$. Table 1 shows the nominal compositions of the commercially available NiCoCrAlY powder (Amdry 365-2, Sulzer Metco) and the Hastelloy ${ }^{\circledR}$ X superalloy substrate. The whole spraying process of HVAF coating was conducted at atmosphere environment and detailed spraying parameters for the HVAF process are summarized in Table 2.

Table 1. Nominal composition of Hastelloy ${ }^{\circledR}$ X substrate and NiCoCrAlY powder

\begin{tabular}{|c|c|c|c|c|c|c|c|c|c|c|}
\hline \multirow{2}{*}{ Material } & \multicolumn{10}{|c|}{ Element (wt \%) } \\
\hline & $\mathrm{Ni}$ & Co & $\mathrm{Cr}$ & $\mathrm{Al}$ & Y & $\mathrm{Fe}$ & Mo & $\mathrm{W}$ & $\mathrm{C}$ & $\mathrm{Mn}$ \\
\hline Hastelloy ${ }^{\circledR} X$ & 47 & 1.5 & 22 & / & / & 18 & 9 & 0.6 & 0.1 & $1 *$ \\
\hline NiCoCrAlY & 47.5 & 23 & 17 & 12 & 0.5 & / & / & / & / & / \\
\hline
\end{tabular}

Table 2. Spray parameters employed in the HVAF process

\begin{tabular}{ll}
\hline Spraying parameters & HVAF \\
\hline Spray distance $(\mathrm{mm})$ & 180 \\
Spray speed $(\mathrm{mm} / \mathrm{s})$ & 2000 \\
Powder rate $(\mathrm{g} / \mathrm{min})$ & 100 \\
Primary gas $(\mathrm{L} / \mathrm{min})$ & 78 \\
Secondary gas $(\mathrm{L} / \mathrm{min})$ & 22.5 \\
\hline
\end{tabular}

\subsection{Isothermal oxidation}

The deposited samples were cut into $10 \times 10 \times 5 \mathrm{~mm}^{3}$ rectangle plates. To eliminate the effect of surface roughness, all the coatings were mechanically ground down to similar thickness $(\sim 200 \mu \mathrm{m})$, with final polishing of $0.05 \mu \mathrm{m}$ using standard metallographic approaches and thoroughly cleaned with acetone prior to oxidation. The isothermal oxidation experiment was performed at $1150{ }^{\circ} \mathrm{C}$ in a chamber furnace at atmosphere environment for duration ranging from 1 to $100 \mathrm{~h}$. The samples were removed from furnace after a required exposure time, air-cooled outside the furnace at room 
temperature for approximately $15 \mathrm{~min}$.

\subsection{Characterization}

X-ray diffraction (XRD, Ultimo IV, Riau, Japan) measurements at $30 \mathrm{kV}$ with $\mathrm{Cu} \mathrm{K \alpha}$ radiation were employed to study the phase composition of the coatings. The spectra were collected in the $2 \theta$ range of $20 \sim 80^{\circ}$ with a step size of $0.02^{\circ}$, and a scanning speed of $0.5^{\circ} / \mathrm{min}$. The microstructure and chemical composition of coatings and thermally grown oxides layer were executed by Scanning electron microscopy (SEM, FEI Nova Nano 230, Netherlands) equipped with energy dispersive X-ray spectroscopy (EDS, Oxford Instruments). To reveal the grain microstructure of the HVAF coating in greater details, thin lamellae of the coating were prepared by a focused ion beam (FIB, GAIA3, Tescan, Czech Republic) and were analysed using a scanning transmission electron microscope (STEM, TALOS F200X, FEI, USA) equipped with an energy dispersive X-ray spectroscopy (EDS, XIS Ultra DLD, Kratos, Japan) system. The details of STEM sample preparation can be found elsewhere [5]. The grain sizes of the $\gamma$ and $\beta$-grains in the HVAF coating were determined by five SEM micrographs with a magnification of $30000 \times$ in conjunction with the TEM analysis using Image $\mathrm{J}$ software (National Institues of Health, USA). The grain sizes in the HVAF-V and HVAF-S coatings were measured using the SEM micrographs combined with FIB etching (FIB-SEM) [19]. The photoluminescence piezospectroscopy (PLPS) was employed to characterize the phase transformation of alumina and residual stress in thermally grown oxides layer using a confocal Raman microprobe (LabRAM HR, Horiba Jobin Yvon, France) with a $532 \mathrm{~nm}$ Nd:YAG laser. The spectra were fitted using a mixed Gaussian-Lorentzian function (Labspec software) to obtain the peak positions. The residual stress was calculated based on the peak shift using the spalled TGO debris as stress free reference. 


\section{Results}

\subsection{The microstructure of coatings}
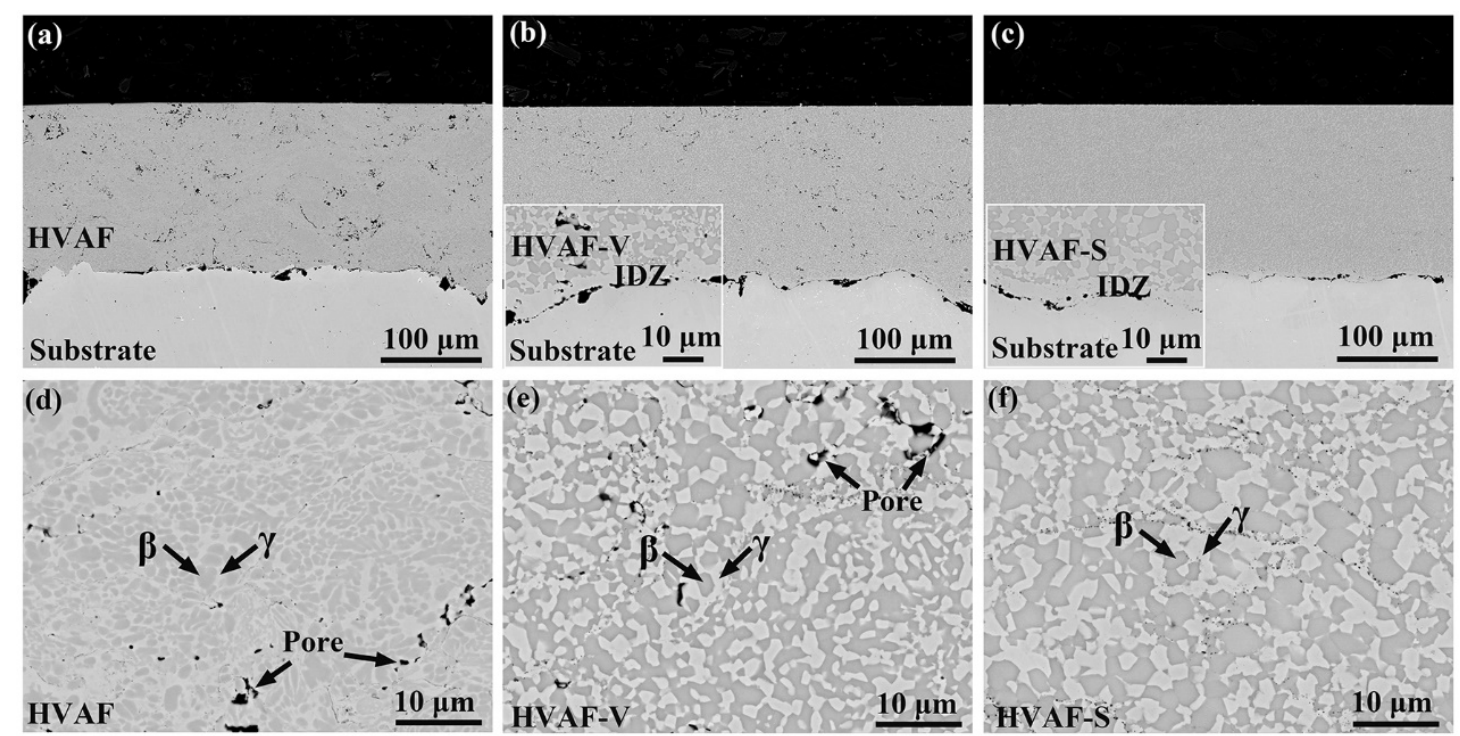

Fig. 1. The cross-sectional BSE micrographs of (a, d) HVAF, (b, e) HVAF-V and (c, f) HVAF-S coatings.

Fig. 1 shows the cross-sectional microstructure of HVAF, HVAF-V and HVAF-S coatings. As can be seen in Fig.1, all coatings were about $200 \mu \mathrm{m}$ in thickness and had the same surface roughness. As presented in Fig. 1d, e and f, all coatings exhibit a twophase microstructure, which comprises the $\gamma$-Ni phase (light contrast) and $\beta$-NiAl phase (dark contrast)[6]. For HVAF-V and HVAF-S coatings (Fig. 1b and c), the thickness of intermediate inter-diffusion zone (IDZ) at coating/substrate interface is $\sim 5 \mu \mathrm{m}$, which indicates an almost same extent of inter-diffusion. Thus the effect of inter-diffusion on the oxidation behavior can be neglected due to thin inter-diffusion layer $(\sim 5 \mu \mathrm{m})$ and thick coating $(\sim 200 \mu \mathrm{m})$. 


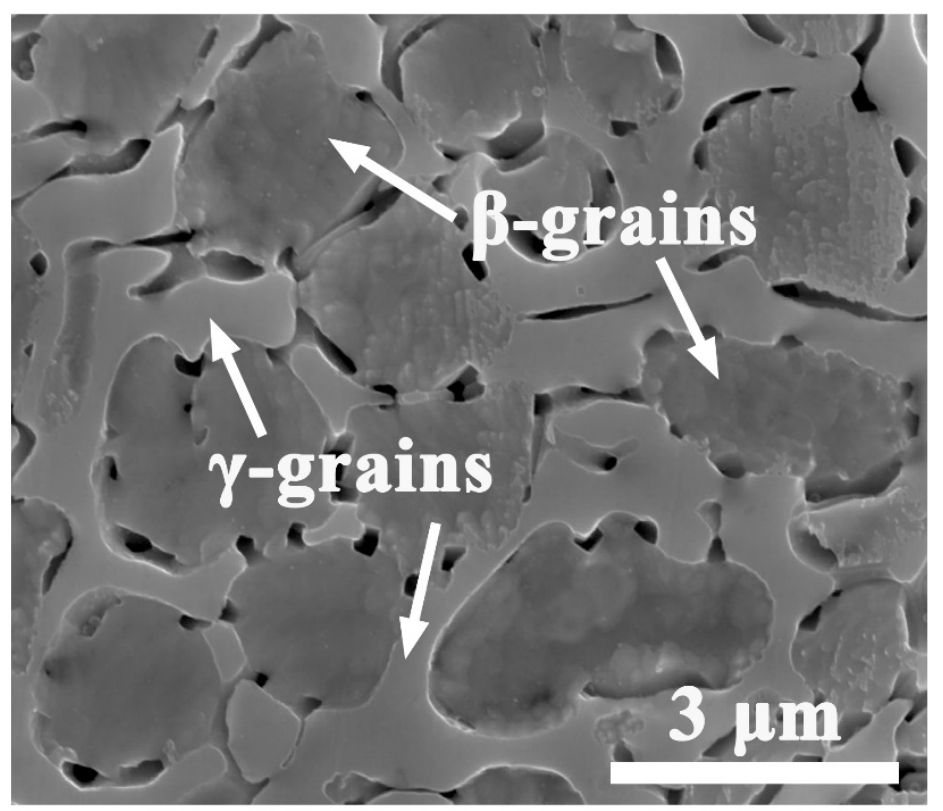

Fig. 2. Surface morphology of the HVAF coating after etching, showing the grain microstructure. The polished samples were etched using a mixture of $50 \mathrm{vol} . \% \mathrm{HCl}$, 50 vol. \% ethanol with 5 wt. \% $\mathrm{CuCl} 2$ dissolved [20].

It should be noted that the microstructures of these coatings shows significant difference in the grain size and porosity. Fig. 2 shows the distribution of $\gamma$-grains and $\beta$-grains in the HVAF coating. The $\beta$-grains are almost equiaxed and the $\gamma$-grains are elongated with a large aspect ratio. The grain size of elongated $\gamma$-grains is defined by the grain width and aspect ratio [5]. The TEM analysis is employed to further reveal the grain size of $\gamma$-grains, as shown in Fig. 3. The distribution of $\gamma$-grains and $\beta$-grains in the HVAF coating is identified by the elemental mapping. The $\mathrm{CoCr}$ enriched grains are $\gamma$-grains and $\mathrm{Al}$ enriched grain are $\beta$-grains, respectively, which is clearly presented in Fig. 3b. The average grain sizes of $\beta$-grains and $\gamma$-grains in the HVAF coating are about $1.83 \mu \mathrm{m}$ and $500 \mathrm{~nm}$ with a large aspect ratio (range from 1 to 10 ) in combination with grain distribution in Fig. 2. The formation of fine $\gamma$-grains in the HVAF coating can be attributed to the severe cold deformation, which involves extremely low deposition temperature and high flight velocity of particle $[5,16]$. 

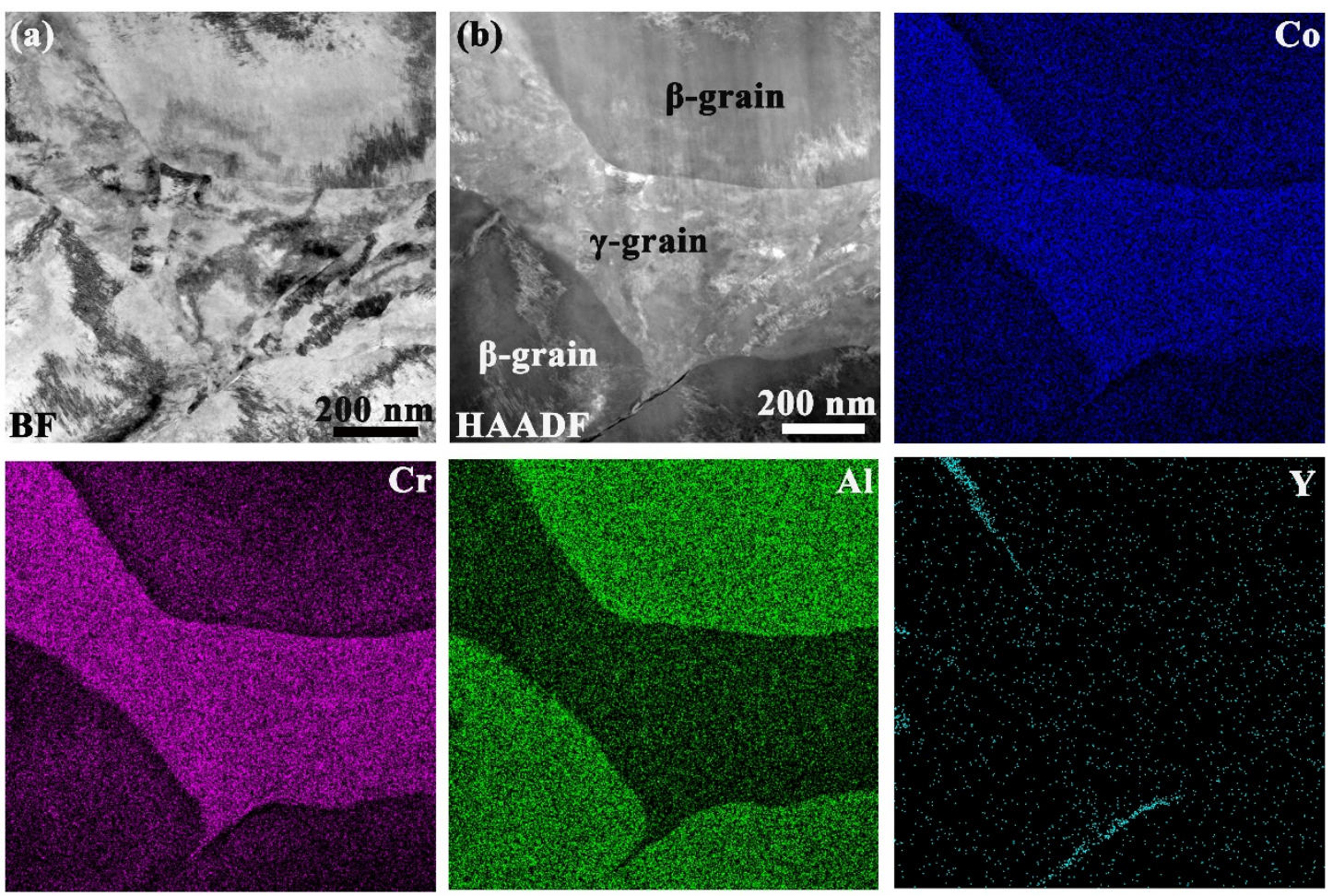

Fig. 3. TEM analysis of the HVAF coating: $(a, b)$ bright-field (BF) TEM micrograph and high-angle annular dark-field (HAADF) STEM micrograph, corresponding to EDS maps of, $\mathrm{Co}, \mathrm{Cr}, \mathrm{Al}$ and $\mathrm{Y}$, respectively.

For the HVAF-V and HVAF-S coatings, the grain size increases to several micrometers and almost equiaxed due to the heat treatment (Fig. 1). Thus the high magnification SEM micrographs combined with FIB etching are employed to determine the grain sizes, which are presented in Fig. 4. Although the $\gamma$-grains and $\beta$-grains are difficult to distinguish after FIB etching, the grain size is uniformly distributed, as shown in Fig. 4a and $\mathrm{b}$. The average grain sizes are about $1.93 \mu \mathrm{m}$ and $1.75 \mu \mathrm{m}$ for HVAF-V and HVAF-S coatings, respectively. Additionally, Y enriched precipitates segregates to the grain boundaries for all coatings due to the the low solubility of Y in the NiCoCrAlY (Fig. 2, 3 and 4) [21, 22]. 

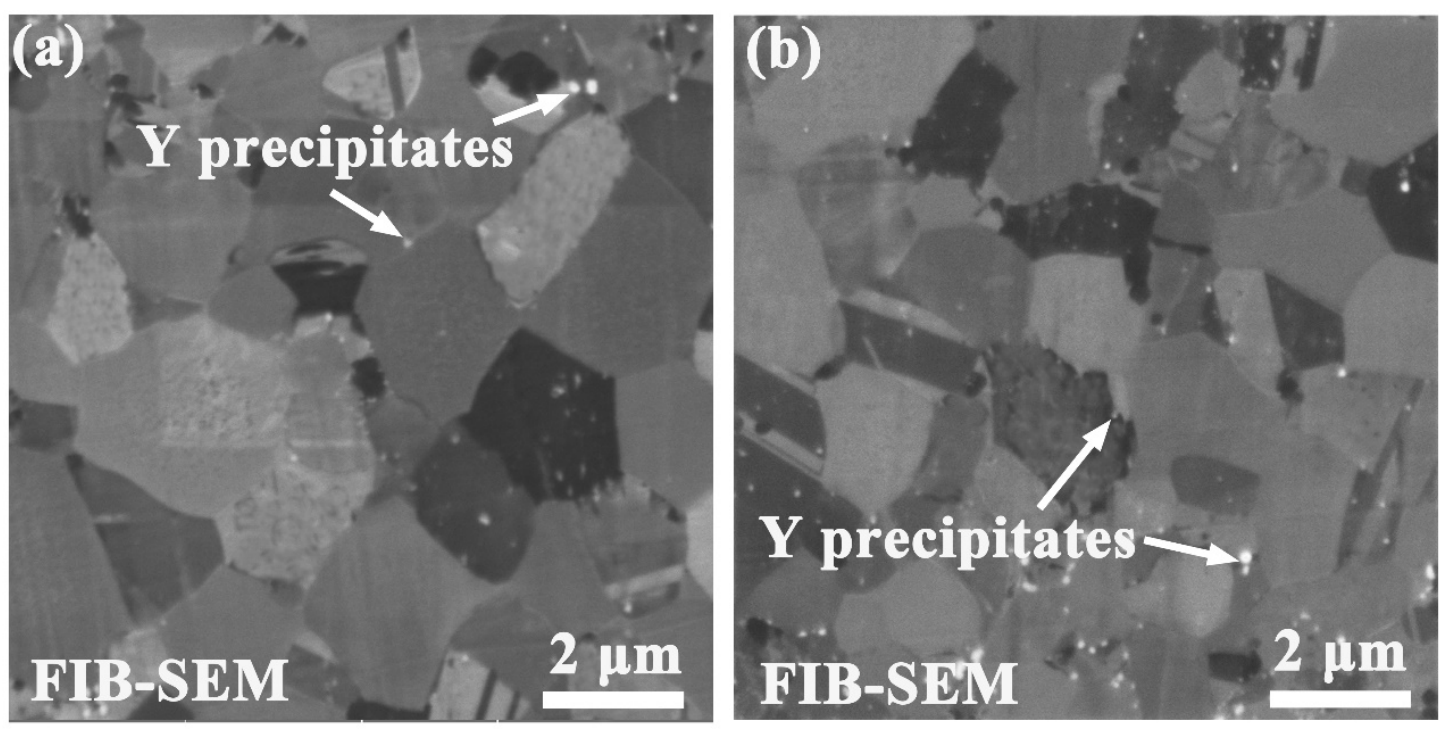

Fig. 4. (a, b) SEM micrographs combined with FIB etching, showing the grain microstructure for HVAF-V and HVAF-S coatings, respectively.

The polished surface morphologies of coatings are presented in Fig. 5 to determine the distribution of pores. Oxide inclusions are hardly detected in either type of coating, which manifests negligible oxidation during the spraying process. For the HVAF coating (Fig. 5a), the pores are distributed at the unmelted particle boundaries and between adjacent particles, which is attributed to insufficient localized plastic deformation during spraying. The microstructure from original particle is retained in the HVAF coating, as the micrograph inserted in Fig. 5a. For the HVAF-V coating, the large-sized pores along unmelted particle boundaries cannot be completely eliminated, although the amount and size of pores are reduced, as shown in Fig. 5b. It is inadvisable to promote the densification of coating by increasing the temperature or time of vacuum heat treatment, which can lead to an intense inter-diffusion between substrate and coating and thereby severely compromise both the oxidation resistance performance of coating and the mechanical properties of substrate [23-25]. Therefore, the spark plasma sintering is employed to realize a higher degree of densification for the HVAF-S coating. Meanwhile, a low degree of inter-diffusion can be controlled due to its capability of fast sintering (Fig. 1c). As shown in Fig. 5c, the HVAF-S coating is fully dense and the pores at the unmelted particle boundaries are hardly seen. The average porosity of 
HVAF, HVAF-V, and HVAF-S coatings, determined by image analysis method referring to literature $[6,26]$, is estimated to be $3.58 \%, 1.96 \%$ and $0.16 \%$, respectively.
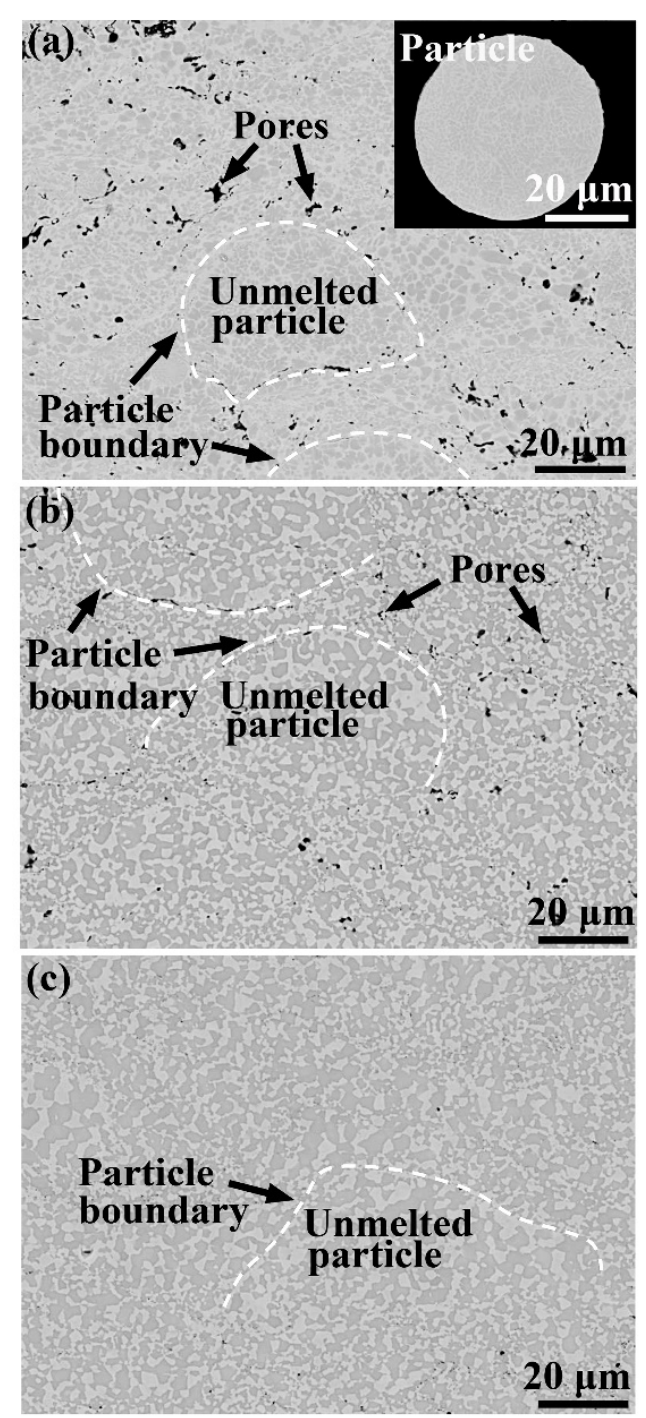

Fig. 5. The BSE micrographs of polished surface of (a) HVAF, (b) HVAF-V and (c) HVAF-S coatings.

\subsection{TGO spallation resistance}

The TGO spallation degree after oxidation from $1 \mathrm{~h}$ to $100 \mathrm{~h}$ at $1150{ }^{\circ} \mathrm{Cis}$ plotted in Fig. 6 to evaluate the oxidation performance of these coatings. To determine the ratio of TGO spallation for all coatings after isothermal oxidation, ten $75 \times$ magnification BSE micrographs are used to obtain the average spallation ratio of TGO and the error bar is the standard deviation. The low magnification BSE micrographs of TGO surface for three types of coatings after isothermal oxidation at $1150^{\circ} \mathrm{C}$ for $50 \mathrm{~h}, 50 \mathrm{~h}$, and $100 \mathrm{~h}$ 
are presented in Fig. 7. It can be clearly seen in Fig. 7b, $\mathrm{d}$ and $\mathrm{f}$ that the spalled section of TGO is shown in white contrast after processing using Image $\mathrm{J}$, so as to further confirm the spallation ratio of TGO. For the HVAF coating, the spalled region can be observed after $25 \mathrm{~h}$ oxidation. The spalled area increases as the oxidation time and attains $\sim 32 \%$ of the whole area of the TGO after $100 \mathrm{~h}$ oxidation. Luo et al [6] reported similar TGO spallation ratio for the HVAF coating after isothermal oxidation at $1150{ }^{\circ} \mathrm{C}$. For the HVAF-V coating, the distinct TGO spallation ( $\sim 11 \%)$ is discovered after $25 \mathrm{~h}$ oxidation. The detachment of TGO increases dramatically with an increase of the oxidation time and exceeds $50 \%$ after $100 \mathrm{~h}$ oxidation. Nevertheless, the TGO formed on the HVAF-S coating is almost intact even after $100 \mathrm{~h}$ exposure. It is clearly indicated that the HVAF-S coating exhibits superior spallation resistance, compared with the HVAF and HVAF-V coatings.

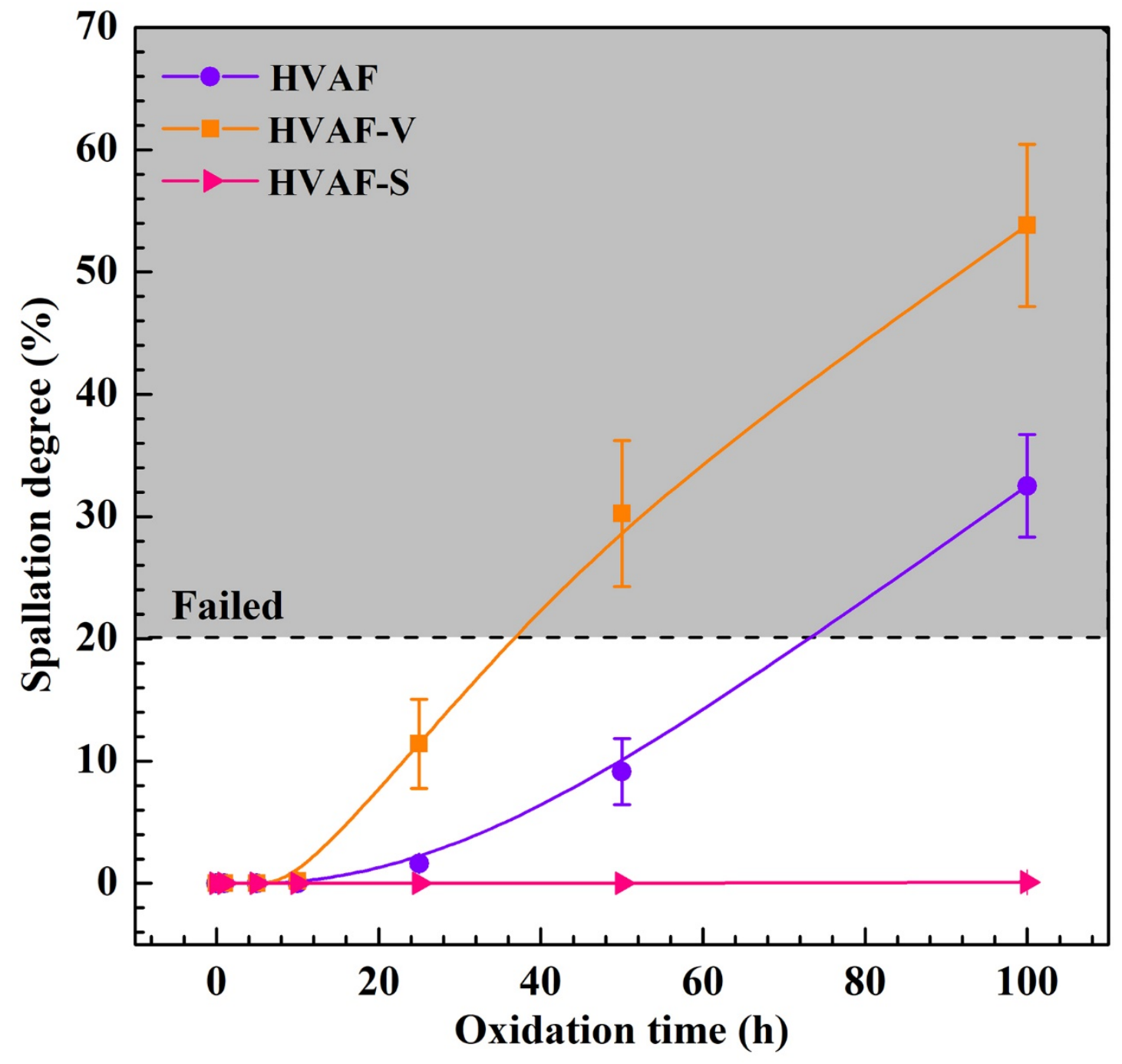


Fig. 6. The spallation degree of TGO formed on the coatings as a function of isothermal oxidation time at $1150{ }^{\circ} \mathrm{C}$ (The spallation degree is defined by the ratio between spalled area and the whole area of the TGO).
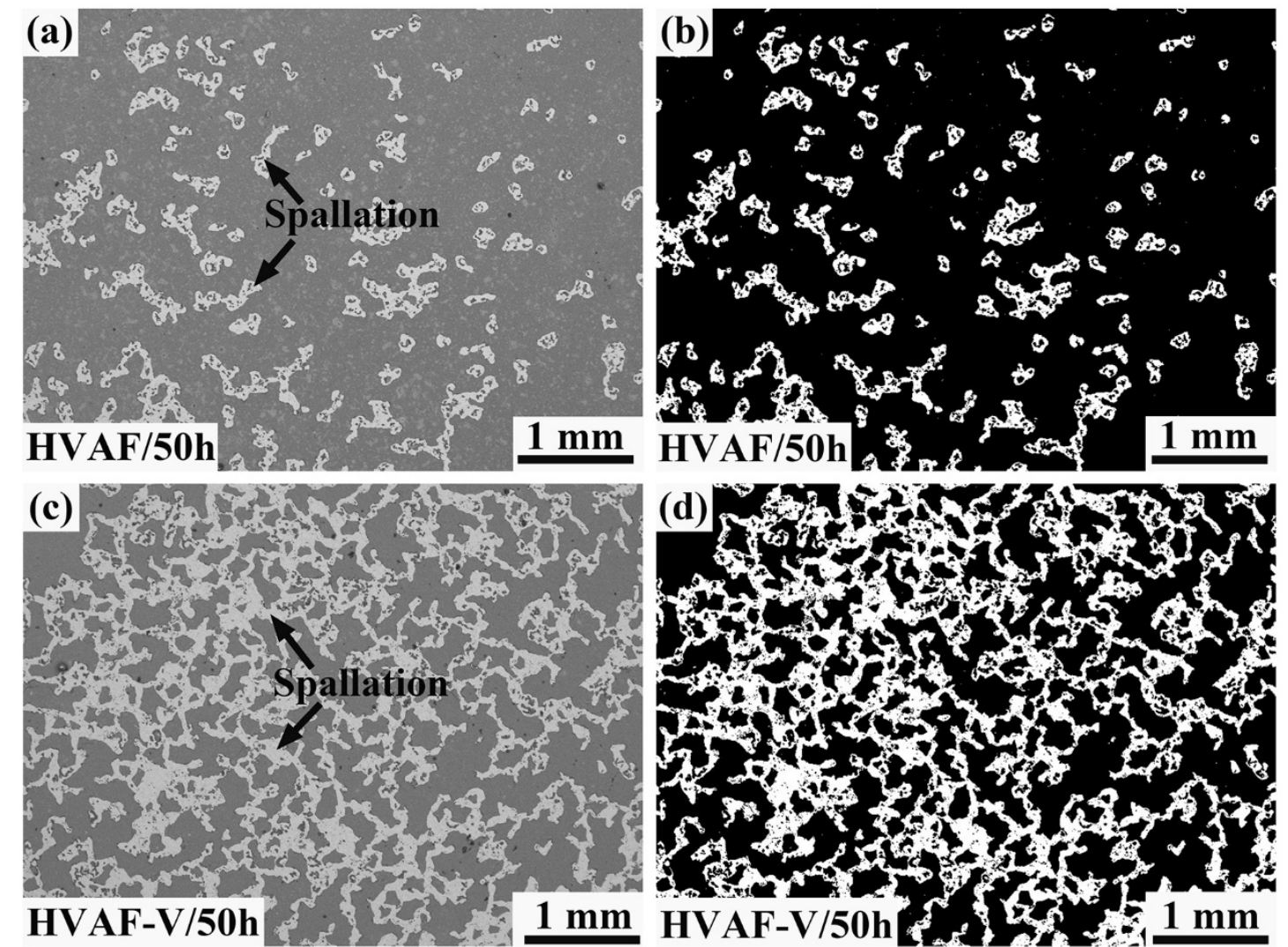

(e)

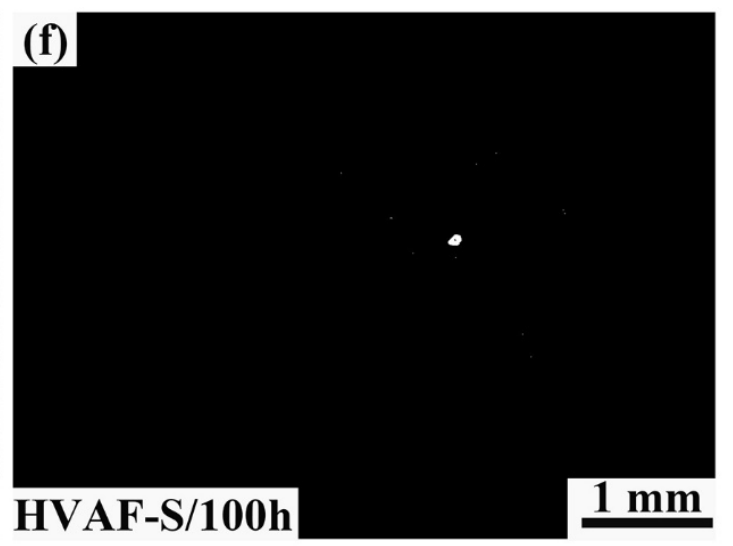

Fig. 7. (a, c and e) BSE micrographs of TGO surface, showing the spallation morphologies of TGO formed on HVAF, HVAF-V and HVAF-S coatings after isothermal oxidation at $1150{ }^{\circ} \mathrm{C}$ for $50 \mathrm{~h}, 50 \mathrm{~h}$, and $100 \mathrm{~h}$, respectively; (b, d and f) processed micrographs of (a, c and e) using Image J, showing the spalled section of TGO in white contrast. 


\subsection{TGO microstructure}

Fig. 8 shows the optical plan-view micrographs of the TGO formed on all coatings after isothermal oxidation for different time at $1150^{\circ} \mathrm{C}$. For the HVAF and HVAF-V coatings, a considerable ratio of spinel (e.g. $\left.(\mathrm{Co}, \mathrm{Ni})(\mathrm{Cr}, \mathrm{Al})_{2} \mathrm{O}_{4}\right)$ corresponding to the blue colored oxides forms in the TGO after oxidation (e.g. Fig. 8a, b, f and g)[6, 27]. Thus the fraction of spinel in the TGO formed on all coatings as a function of oxidation time is measured by quantitative image analysis, which is summarized in Fig. 9. For the HVAF coating, the ratio of spinel reaches to $\sim 7.1 \%$ after $10 \mathrm{~h}$ oxidation and increases to $9.2 \%$ after $25 \mathrm{~h}$ oxidation. When the TGO starts to suffer apparent spallation after $50 \mathrm{~h}$ oxidation (Fig. $8 \mathrm{c}$ ), the ratio of spinel declines to $\sim 4.4 \%$. Additionally, the spinel almost disappear after $100 \mathrm{~h}$ oxidation (Fig. 8d). For the HVAF-V coating, the amount of spinel is minor after $10 \mathrm{~h}$ oxidation and attains $\sim 5.1 \%$ after $25 \mathrm{~h}$ oxidation. Similarly, the spinel gradually reduce with the spallation of the TGO after $50 \mathrm{~h}$ oxidation (Fig. 8g) and are hardly seen after $100 \mathrm{~h}$ oxidation (Fig. $8 \mathrm{~h}$ ). Spinel prefers to form around the pores due to the locally insufficient aluminum supply from the coating [6]. Therefore, the lower amount of spinel for HVAF-V coating can be attributed to the higher degree of densification, as compared with the HVAF coating. Nevertheless, the HVAF-V coating exhibits a higher TGO spallation degree, while the amount of spinel is lower than that for the HVAF coating (Fig. 6 and 9). For the HVAF-S coating, the spinel is hardly detected in TGO even after $100 \mathrm{~h}$ oxidation (Fig. 8i-m). 

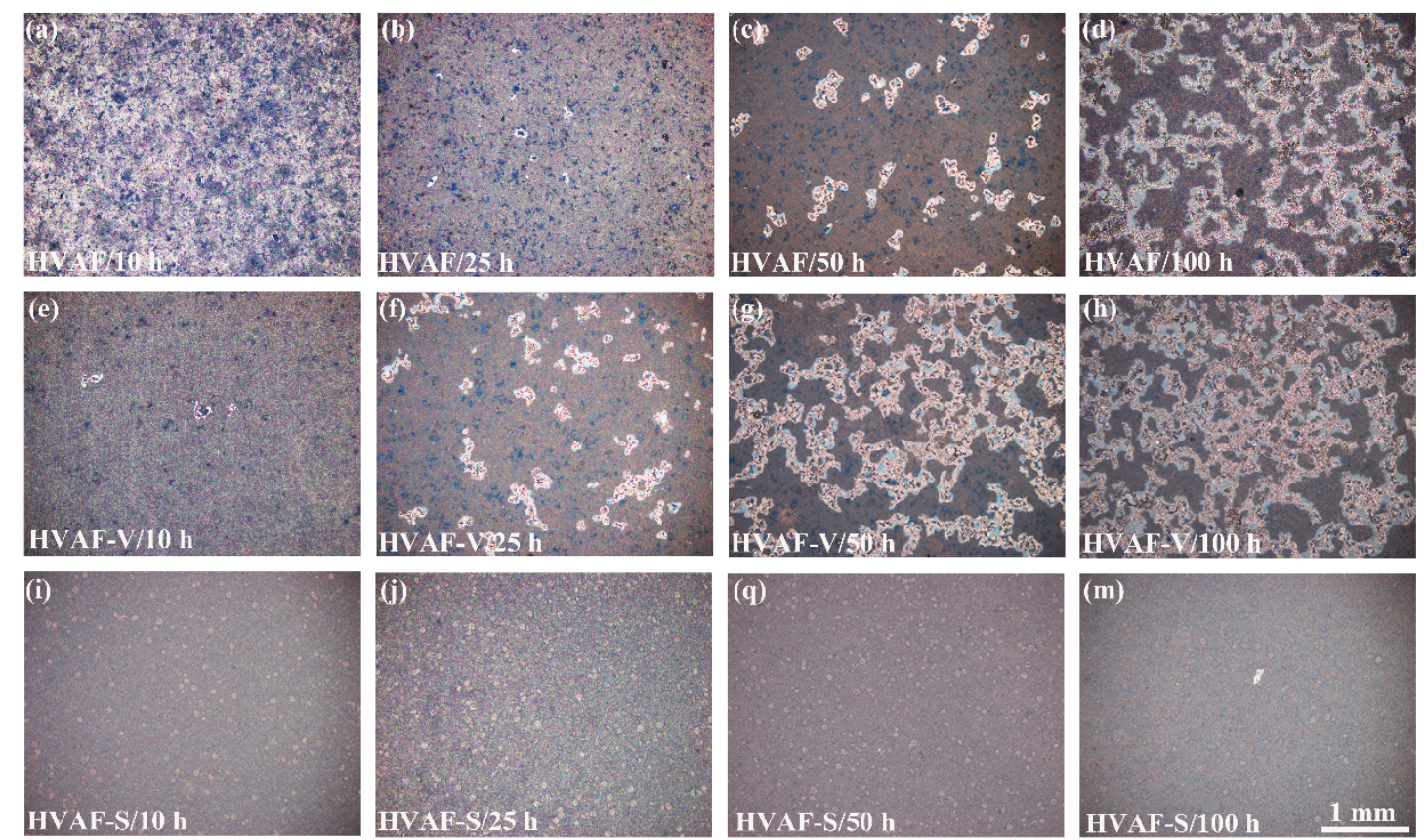

(m)

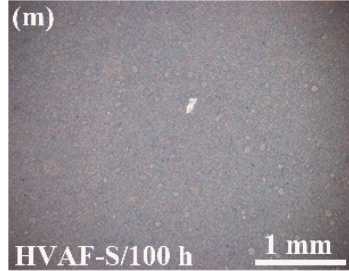

Fig. 8. The optical plan-view micrographs of the TGO formed on HVAF, HVAF-V and HVAF-S coatings after isothermal oxidation at $1150{ }^{\circ} \mathrm{C}$ for $10 \mathrm{~h}, 25 \mathrm{~h}, 50 \mathrm{~h}$ and $100 \mathrm{~h}$, respectively. 


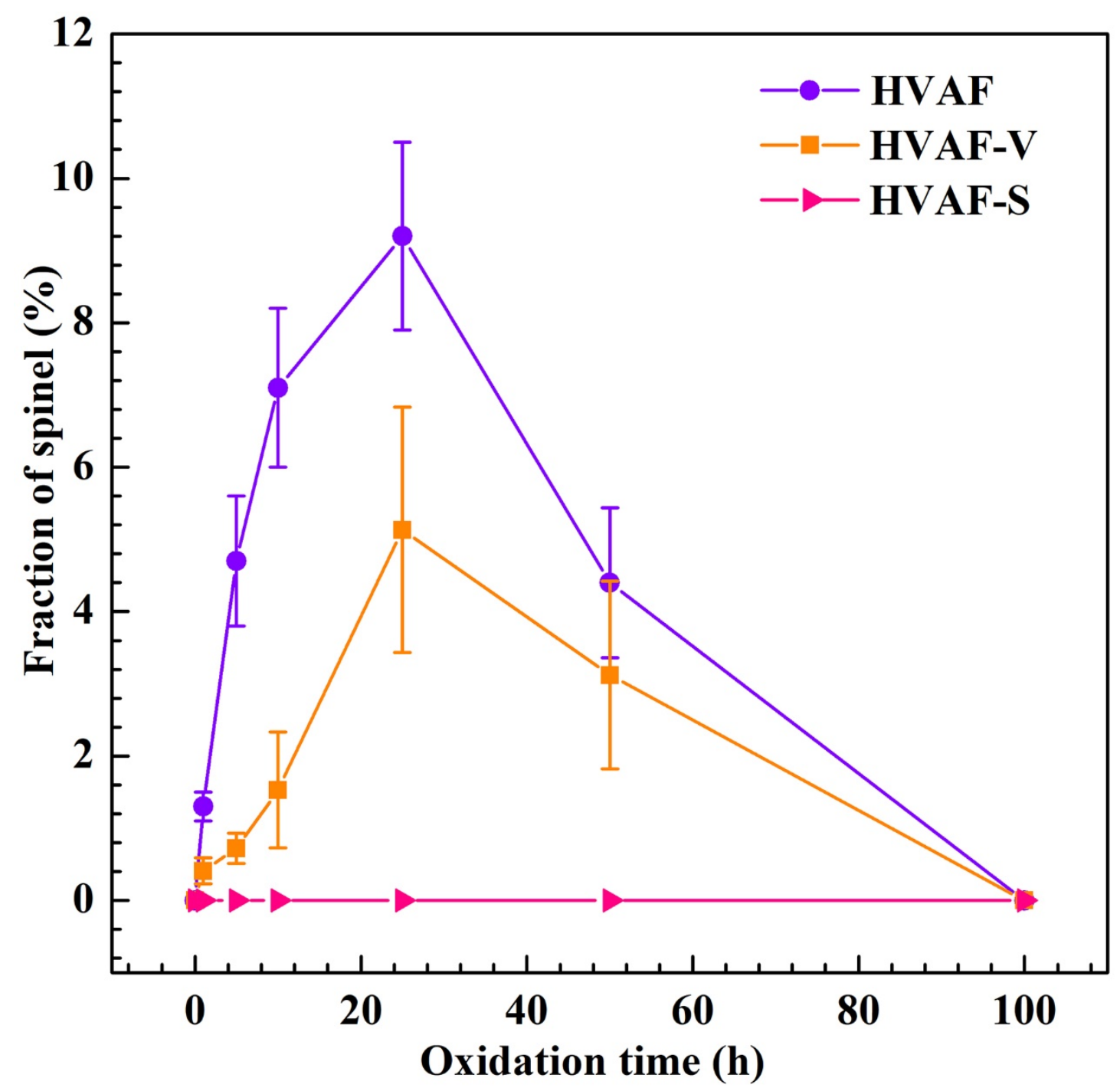

Fig. 9. The fraction of spinel in the TGO formed on all coatings as a function of isothermal oxidation time at $1150^{\circ} \mathrm{C}$. The error bar shows the standard deviation.

Based on the results displayed in Fig. 6 and 8, the spallation ratio of TGO exhibits obvious difference for the HVAF and HVAF-V coatings after $50 \mathrm{~h}$ oxidation. However, for the HVAF-S coating, only minor quantity of spallation of TGO can be observed even after $100 \mathrm{~h}$ oxidation (Fig. 6). Therefore, Fig. 10 compares the surface and crosssectional morphologies for the HVAF, HVAF-V and HVAF-S coatings after isothermal oxidation at $1150^{\circ} \mathrm{C}$ for $50 \mathrm{~h}, 50 \mathrm{~h}$, and $100 \mathrm{~h}$, respectively. For the HVAF coating (Fig. 10a), the internal oxides predominantly grow at unmelted particle boundaries and extend into the coating, which can be also found at TGO/coating interface (Fig. 10b). For the HVAF-V coating (Fig. 10c and d), the presence of internal oxides is still inevitable, in spite of a relatively lower amount of pores in the coating, which can be 
attributed to the remaining pores at unmelted particle boundaries (Fig. 5b). However, for the HVAF-S coating (Fig. $10 \mathrm{~g}$ and $\mathrm{h}$ ), no internal oxides can be observed at $\mathrm{TGO} /$ coating interface even after $100 \mathrm{~h}$ oxidation due to the fully dense microstructure of coating (Fig. 5c). The only interfacial imperfection observed at spalled region is the interface pore, which is probably driven by the Kirkendall effect [20]. Away from the spalled region, the TGO still keeps good adhesion. It is clearly indicated that the pores at unmelted particle boundaries lead to the formation of internal oxides.

The detrimental effect of internal oxides on the oxidation behavior of HVAF and HVAFV coatings should be noted. As shown in Fig. $10 \mathrm{~b}$ and e, in these regions of internal oxides, the enhanced Al-depletion zones are observed, which cause localized insufficient aluminum supply from the coatings to form alumina. Thus the spinel will form as a result of depletion of $\mathrm{Al}$ and enrichment of $\mathrm{Co}, \mathrm{Ni}$ and $\mathrm{Cr}$ from the underlying coatings, which leads to the breakaway oxidation in the coatings (Fig. 10c and f) [9, 28]. In these regions of no internal oxides, the aluminum is uniformly depleted (Fig. $10 \mathrm{~b}$ and e). The spinel is brittle and fast growing in comparison to alumina, where the nucleation and propagation of cracks occur easily (Fig. 10f) [8, 9, 29]. Additionally, the spinel mainly consists of $(\mathrm{Co}, \mathrm{Ni})(\mathrm{Cr}, \mathrm{Al})_{2} \mathrm{O}_{4}$ spinel in combination with the EDS result in Fig. 10c1. For the HVAF-S coating (Fig. 10h and i), the uniform and continuous TGO with a smooth $\mathrm{TGO} /$ coating interface is observed, where the internal oxidation is completely inhibited. 

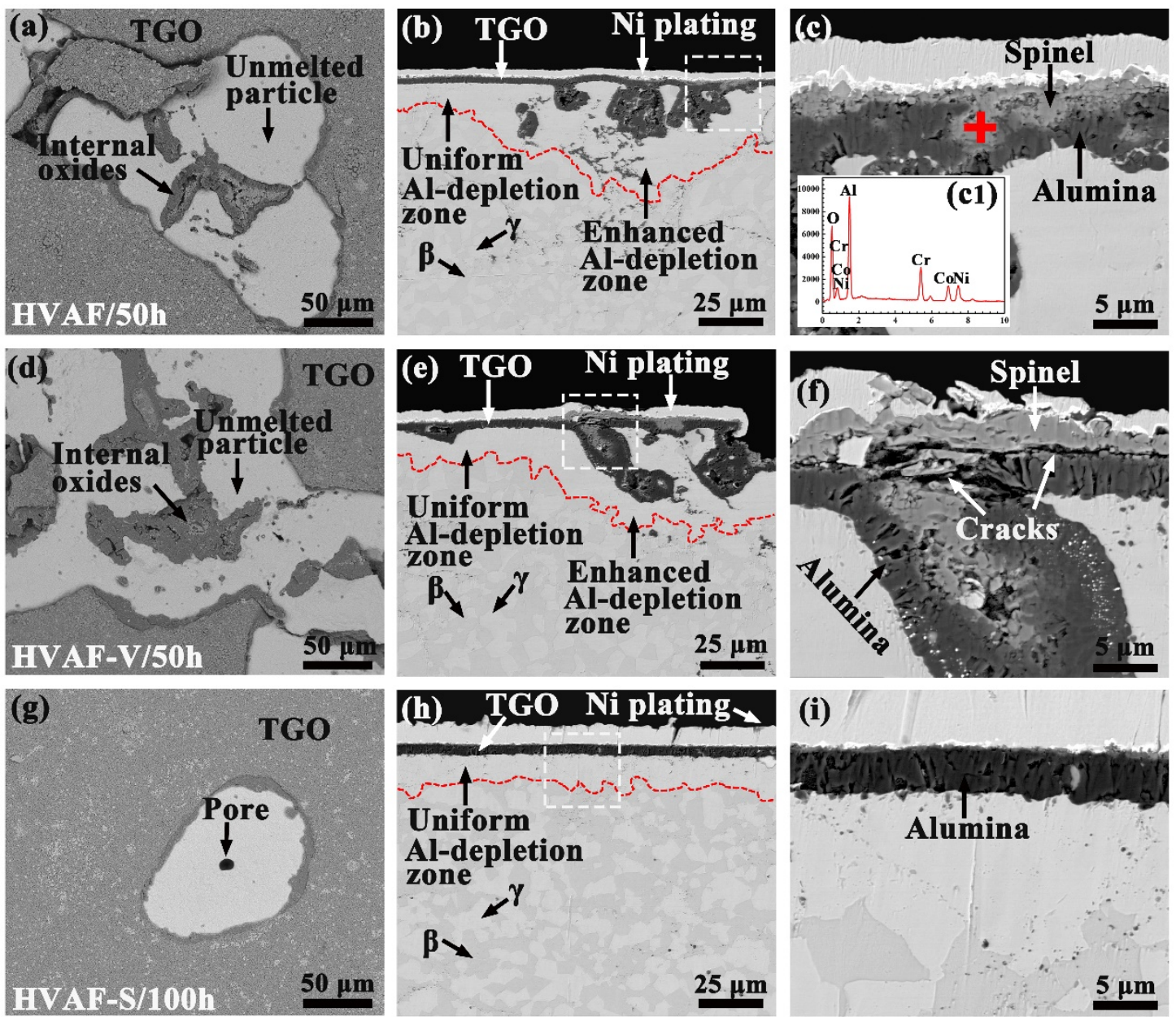

Fig.10. (a, d, and g) BSE micrographs at spalled regions, showing the surface morphologies of HVAF, HVAF-V and HVAF-S coatings after isothermal oxidation at $1150{ }^{\circ} \mathrm{C}$ for $50 \mathrm{~h}, 50 \mathrm{~h}$, and $100 \mathrm{~h}$, respectively; (b, e, and h) BSE micrographs of crosssection of TGO, giving an overview of the TGO on HVAF, HVAF-V and HVAF-S coatings after isothermal oxidation at $1150{ }^{\circ} \mathrm{C}$ for $50 \mathrm{~h}, 50 \mathrm{~h}$, and $100 \mathrm{~h}$, respectively; (c, f, and i) high magnification BSE micrographs of areas marked by white rectangles in (b, e, and h), showing the cross-sectional microstructure of TGO; (c1) a EDS result of area marked by red crosses in (c), showing the presence of all base metal elements $((\mathrm{Ni}+\mathrm{Co}):(\mathrm{Cr}+\mathrm{Al}) \approx 0.5)$.

Fig. 11 shows the fracture morphologies of TGO after isothermal oxidation at $1150{ }^{\circ} \mathrm{C}$ for $25 \mathrm{~h}$. A double-layered TGO structure consisting of an equiaxed outer layer and a columnar inner layer is developed on all coatings. The formation of double layer scale structure results from the concurrent inward oxygen diffusion and outward aluminum diffusion [30-33]. The segregation of reactive element ions (e.g. Y) to the $\mathrm{Al}_{2} \mathrm{O}_{3}$-based 
TGO grain boundaries will inhibit the outward aluminum transport. Thus the dominant growth mechanism of TGO is inward oxygen diffusion along the $\mathrm{Al}_{2} \mathrm{O}_{3}$ grain boundaries [32, 34-37]. In short, the TGO growth mechanism is same for three types of coatings.
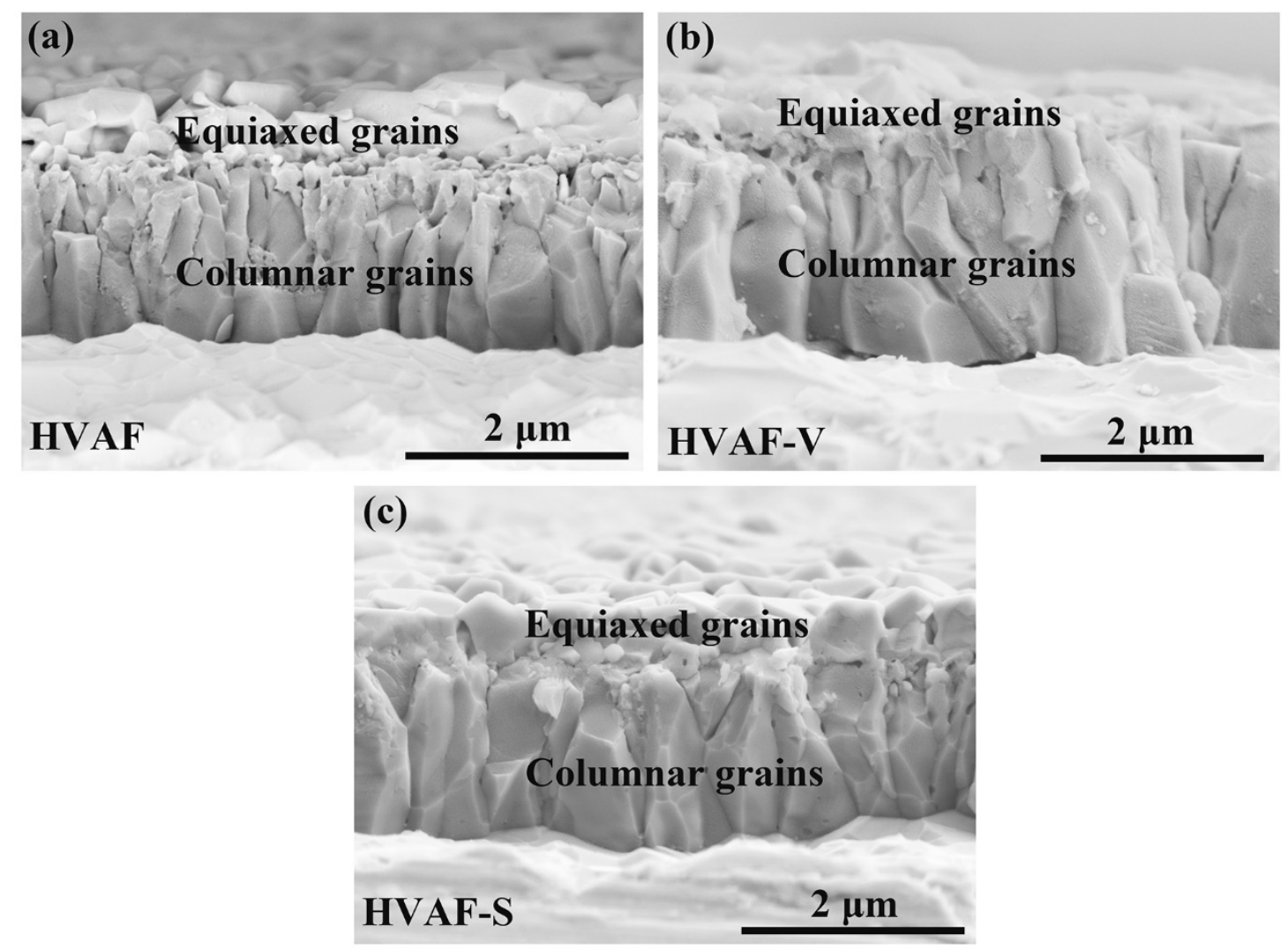

Fig. 11. The fracture section of TGO formed on (a) HVAF, (b) HVAF-V and (c) HVAFS coatings after isothermal oxidation at $1150{ }^{\circ} \mathrm{C}$ for $25 \mathrm{~h}$.

\subsection{Oxides growth kinetics}

Fig. 12 shows the average thickness of the TGO formed on all coatings as a function of the oxidation time at $1150{ }^{\circ} \mathrm{C}$, which is measured at 50 equidistance points distributed through the cross-sectional area of the TGO divided by the length of interface with a step size of $20 \mu \mathrm{m}$. The error bar is the standard deviation of 50 equidistance points. Up to an oxidation time of $25 \mathrm{~h}$, the HVAF coating shows the lowest TGO growth rate. However, the thickness of TGO on the HVAF-S coating is $\sim 2.8 \mu \mathrm{m}$ after $50 \mathrm{~h}$ oxidation, which is lower than that of HVAF coating $(\sim 3.2 \mu \mathrm{m})$ and HVAF-V coating $(\sim 3.8 \mu \mathrm{m})$. After $100 \mathrm{~h}$ oxidation, the difference of the thickness of TGO become more apparent 
(4.1 $\mu \mathrm{m}$ for HVAF coating, $4.8 \mu \mathrm{m}$ for HVAF-V coating, and $3.5 \mu \mathrm{m}$ for HVAF-S coating). In general, the HVAF-S coating shows the lowest TGO growth rate for the long-term oxidation $(>25 \mathrm{~h})$. Meanwhile, the HVAF-V exhibits the highest TGO growth rate. The reasons for this difference in TGO growth rate for all coatings will be discussed later.

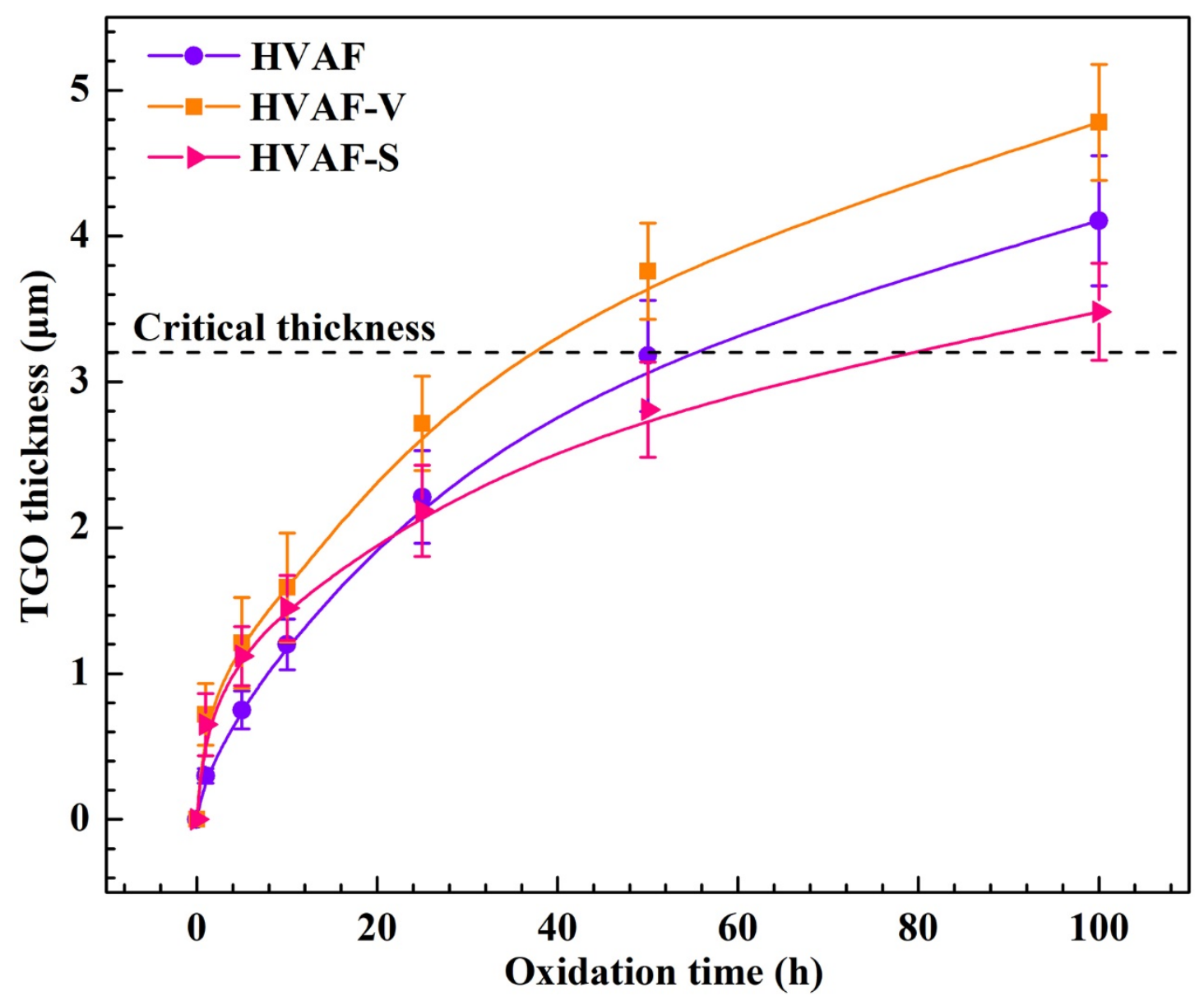

Fig. 12. Kinetics of isothermal oxidation of the HVAF, HVAF-V and HVAF-S coatings at $1150{ }^{\circ} \mathrm{C}$. The horizontal dash line shows the critical thickness of thermally grown oxides (TGO) layer for the propagation of the edge initiated cracks without arrest. 
3.5. Phase transformation of TGO in the early stage
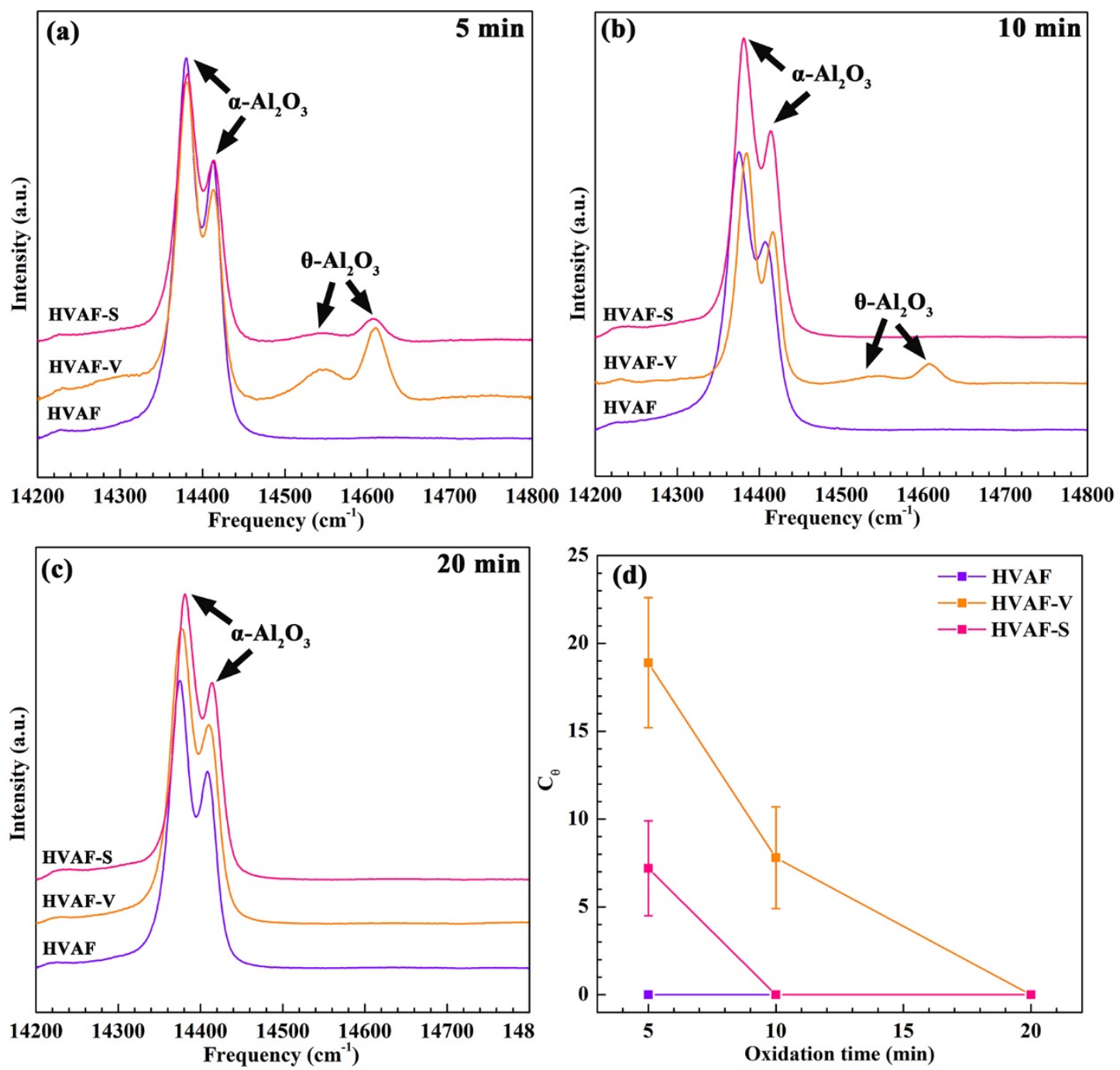

Fig. 13. The PLPS spectra of $\mathrm{Al}_{2} \mathrm{O}_{3}$ scale formed on all coatings after oxidation for: (a) $5 \mathrm{~min}$, (b) $10 \mathrm{~min}$, and (c) $20 \mathrm{~min}$, and (d) shows the evolution of $\theta-\mathrm{Al}_{2} \mathrm{O}_{3}$ content with the oxidation time.
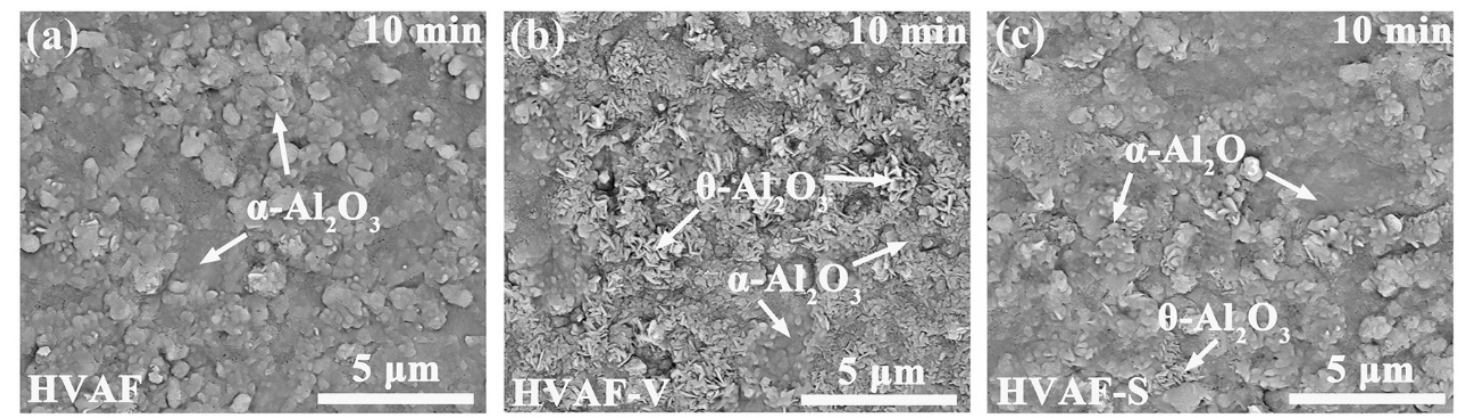

Fig. 14. The surface morphologies of TGO formed on the HVAF, HVAF-V, and HVAF-S coatings after isothermal oxidation for $10 \mathrm{~min}$ at $1150{ }^{\circ} \mathrm{C}$. 
It is well established that $\mathrm{NiCoCrAlY}$ coating primarily forms $\alpha-\mathrm{Al}_{2} \mathrm{O}_{3}$ during oxidation, but transient alumina, particularly $\theta-\mathrm{Al}_{2} \mathrm{O}_{3}$ is always found in the early oxidation stage $[5,20]$. The phase transformation rate of $\theta-\mathrm{Al}_{2} \mathrm{O}_{3}$ to $\alpha-\mathrm{Al}_{2} \mathrm{O}_{3}$ has a non-negligible contribution to the overall TGO growth rate, due to the much faster growth rate of $\theta$ $\mathrm{Al}_{2} \mathrm{O}_{3}$ than $\alpha-\mathrm{Al}_{2} \mathrm{O}_{3}$ [20]. Thus the PLPS spectra are collected to identify the composition and evolution of transient alumina in the early time [20, 38]. Fig. 13 shows the PLPS spectra of transient alumina and the evolution of $\theta-\mathrm{Al}_{2} \mathrm{O}_{3}$ with the oxidation time. The peaks near the frequencies of $14,402 \mathrm{~cm}^{-1}$ and $14,432 \mathrm{~cm}^{-1}$ belong to $\alpha-\mathrm{Al}_{2} \mathrm{O}_{3}$, and the peaks near the frequencies of $14,575 \mathrm{~cm}^{-1}$ and $14,645 \mathrm{~cm}^{-1}$ stand for $\theta$ $\mathrm{Al}_{2} \mathrm{O}_{3}$. The content of $\theta-\mathrm{Al}_{2} \mathrm{O}_{3}, C_{\theta}$, in the $\mathrm{Al}_{2} \mathrm{O}_{3}$ scale can be roughly estimated using the following relationship [20,38]:

$$
C_{\theta}=\frac{A_{14575}+A_{14645}}{A_{14402}+A_{14432}+A_{14575}+A_{14645}}
$$

where A denotes the area of characteristic peaks and the subscript represents the peak frequency.

After 5 min oxidation, both $\theta-\mathrm{Al}_{2} \mathrm{O}_{3}$ and $\alpha-\mathrm{Al}_{2} \mathrm{O}_{3}$ are formed on the HVAF-V and HVAF-S coatings. It should be noted that the content of $\theta-\mathrm{Al}_{2} \mathrm{O}_{3}$ for the HVAF-V coating $(18.9 \%)$ is significantly higher than that for the HVAF-S coating $(7.1 \%)$. However, no $\theta-\mathrm{Al}_{2} \mathrm{O}_{3}$ is detected for the HVAF coating. After 10 min oxidation, about $7.9 \% \theta-\mathrm{Al}_{2} \mathrm{O}_{3}$ remains on the HVAF-V coating, while for the HVAF and HVAF-S coatings, there is almost no $\theta-\mathrm{Al}_{2} \mathrm{O}_{3}$. When the oxidation time increases to 20 min, no $\theta-\mathrm{Al}_{2} \mathrm{O}_{3}$ is detected on the either sample. Based on the above, the phase transformation rate of $\theta$ to $\alpha-\mathrm{Al}_{2} \mathrm{O}_{3}$ in the early stage is in the order: HVAF $>$ HVAF-S $>$ HVAF-V. Fig. 14 shows the distribution of $\theta-\mathrm{Al}_{2} \mathrm{O}_{3}$ and $\alpha-\mathrm{Al}_{2} \mathrm{O}_{3}$ in TGO for three types of coatings after $10 \mathrm{~min}$ at $1150{ }^{\circ} \mathrm{C}$. As shown in Fig. 14b, the blade-like morphology on the outer surface of TGO for the HVAF-V coating is observed, which indicates the presence of a considerable amount of $\theta-\mathrm{Al}_{2} \mathrm{O}_{3}$ [39]. For the HVAF-S coating (Fig. 14c), the TGO mainly consists of $\alpha-\mathrm{Al}_{2} \mathrm{O}_{3}$. Only minor quantity of $\theta-\mathrm{Al}_{2} \mathrm{O}_{3}$ can be seen, which is hardly detected by PLPS technique due to the low content of $\theta-\mathrm{Al}_{2} \mathrm{O}_{3}$ (Fig. 13b). For the HVAF coating (Fig. 14a), the TGO comprises $\alpha-\mathrm{Al}_{2} \mathrm{O}_{3}$ and no $\theta-\mathrm{Al}_{2} \mathrm{O}_{3}$ 
can be found. These results agree well with the PLPS spectra presented in Fig. 13b and d.

\subsection{TGO stress}

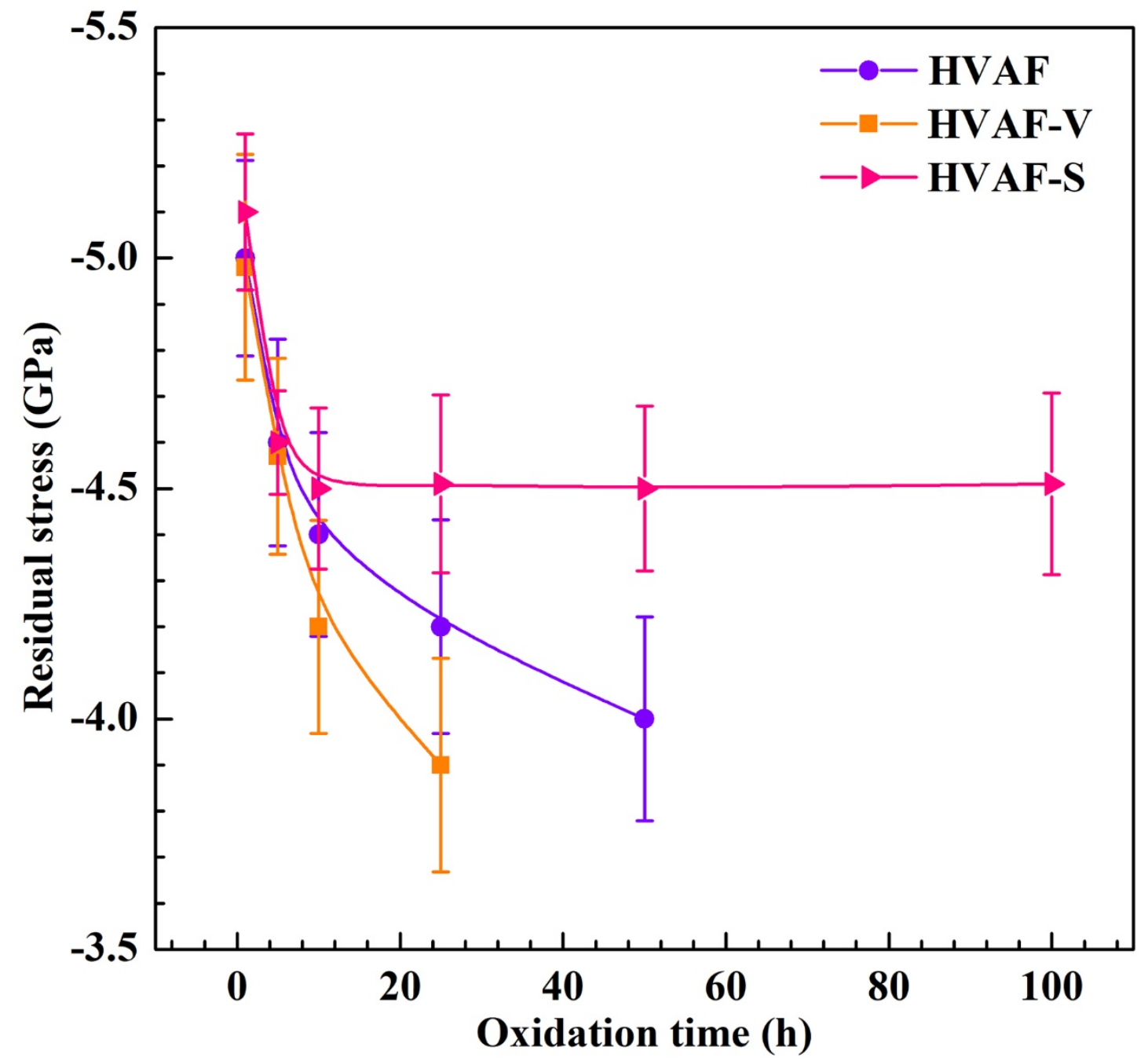

Fig. 15. The residual stress of TGO formed on all coatings as a function of isothermal oxidation time at $1150{ }^{\circ} \mathrm{C}$. Each data point represented by solid symbol in this graph is measured from separate samples and represents the average value of 625 measurements. The error bar shows the standard deviation of 625 measurements.

The driving force for TGO delamination derives from the residual stress in TGO, which comes from the thermal mismatch stress and the growth stress [20, 40]. As presented in Fig. 8 and 10, much spinel ((e.g. $\left.\left.(\mathrm{Co}, \mathrm{Ni})(\mathrm{Cr}, \mathrm{Al})_{2} \mathrm{O}_{4}\right)\right)$ forms in the TGO, where the cracks nucleation and propagation occur easily due to the high brittleness and low 
adherence of spinel in comparison to alumina and stress concentration induced by locally rapid volume expansion. [9, 41, 42]. However, away from the spinel, the TGO predominantly consists of $\alpha-\mathrm{Al}_{2} \mathrm{O}_{3}$ phase. To evaluate the driving force for TGO delamination, the TGO residual stress around and away from the spinel is respectively determined by PLPS technique [20, 43]. Assuming the TGO/coating interface is flat, the residual stress $\sigma$ in the TGO refers to the equi-biaxial stress, which can be calculated by the equation [20, 44, 45]:

$$
\Delta v=5.07 \sigma
$$

where $\Delta v$ is peak shift of $\mathrm{R} 2$ line and the peak shift is obtained using the spalled TGO debris as stress free reference. Fig. 15 shows the evolution of residual stress in the TGO away from spinel as a function of oxidation time at $1150{ }^{\circ} \mathrm{C}$. As presented in the Fig. 6 , the ratio of TGO spallation exceeds $20 \%$ after $50 \mathrm{~h}$ oxidation for the HVAF coating and after $25 \mathrm{~h}$ oxidation for HVAF-V coating, which is defined as failed. Thus the value of residual stress for these samples is not recorded. Two significant features can be found in the Fig. 15. First, the initial rapid decline in the residual stress is observed for the all coatings, which is probably attributed to the stress relaxation mechanism (e.g. creep or plastic deformations) $[46,47]$. Second, the residual stress remains at a stable level ( $4.5 \mathrm{GPa})$ after $10 \mathrm{~h}$ oxidation for HVAF-S coating. However, the residual stress shows gradually decrease after $10 \mathrm{~h}$ oxidation for the HVAF and HVAF-V coatings. It should be specially noted that the HVAF-V coating exhibits a faster decrease in the residual stress, as compared with the HVAF coating. Based on the above analysis, the stability of residual stress for all coatings can be ranked as following: HVAF-S $>$ HVAF $>$ HVAF-V.

It is clearly exhibited in Fig. 8 and 10 that the spallation tends to initiate from spinel zones in the TGO formed on the HVAF and HVAF-V coatings. To map the distribution of residual stress around the spinel, PLPS measurements are conducted a grid of $100 \times 100 \mu \mathrm{m}$ with a step size of $2 \mu \mathrm{m}$. Fig. 16 shows the distribution of TGO stress around the spinel after $25 \mathrm{~h}$ oxidation. For the HVAF coating (Fig. 16a and b) and HVAF-V coating (Fig. 16c and d), the residual stress relaxation around the spinel can be clearly observed, which is probably induced by the nucleation and propagation of 
interfacial cracks. For the HVAF-S coating (Fig. 16e and f), the distribution of residual stress is relatively uniform due to the absence of spinel. In addition, the level of residual stress corresponding to the color scale in Fig. $16 \mathrm{f}$ is in agreement with the level ( $\sim 4.5$ GPa) presented in Fig. 15. It is demonstrated that the spinel imperfection in the TGO plays a crucial role in the initiation of TGO spallation [48-50]. The HVAF-S coating obtains a uniform $\alpha-\mathrm{Al}_{2} \mathrm{O}_{3}$ scale after long term oxidation, which is beneficial to maintaining a good interfacial adhesion.
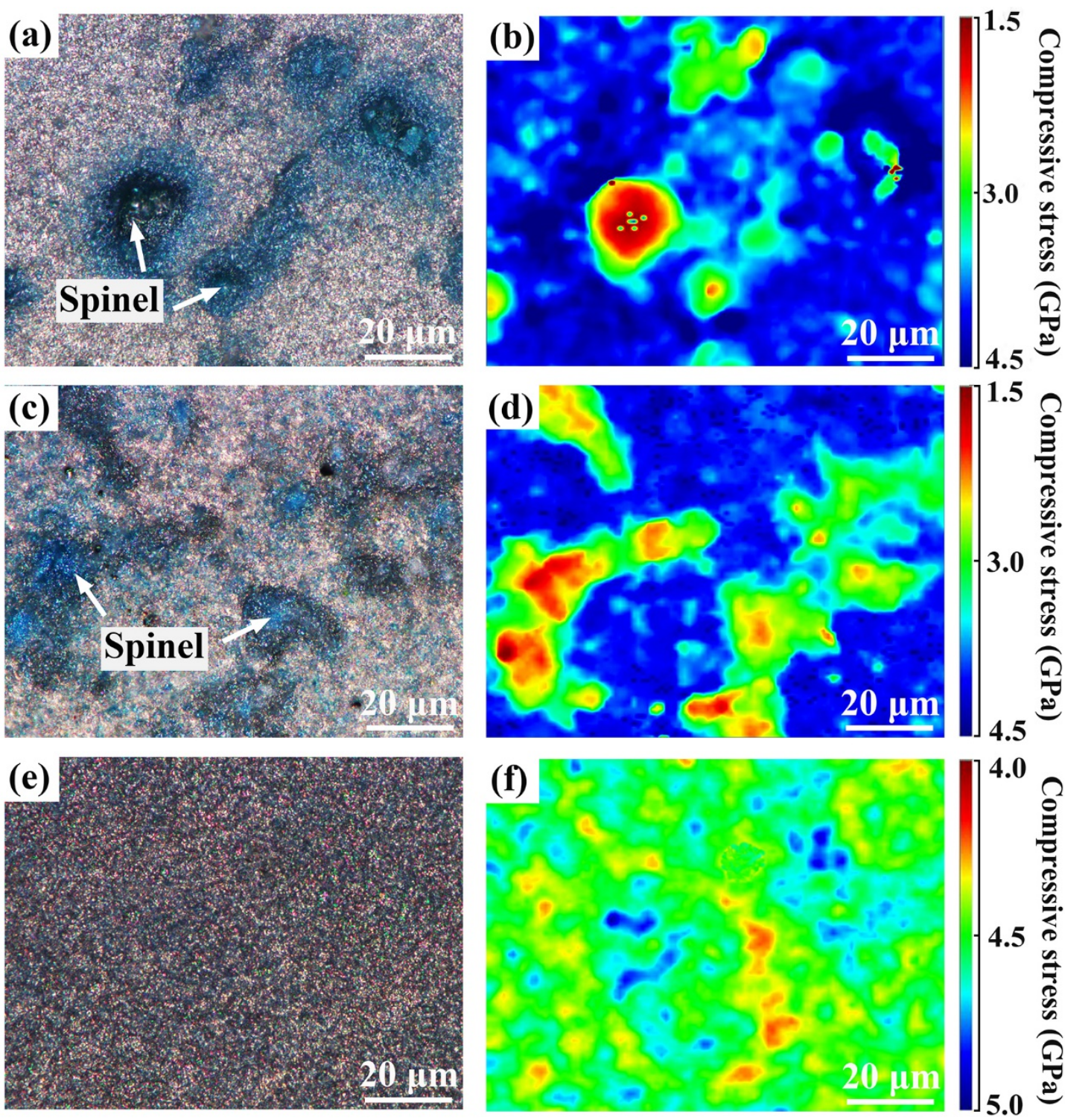

Fig. 16. The optic micrographs and corresponding distribution of the residual stress around the spinel in the TGO formed on the (a, b) HVAF coating, (c, d) HVAF-V coating and (e, f) HVAF-S coating. 


\section{Discussion}

\subsection{Effect of coating microstructure on the phase transformation of aluminum oxide}

As presented in Section 3.5, a different phase transformation rate of alumina for the three types of coating is observed in Fig. 13. The HVAF coating shows the fastest phase transformation rate of $\theta-\mathrm{Al}_{2} \mathrm{O}_{3}$ to $\alpha-\mathrm{Al}_{2} \mathrm{O}_{3}$, while $\mathrm{HVAF}-\mathrm{V}$ coating shows the slowest transformation rate.

It has been extensively reported that the phase transformation rate of alumina can be affected by surface roughness, reactive elements doping (e.g. Y, Hf, and Zr), crystallographic defects (grain sizes and dislocations) $[5,20,51,52]$. The effect of surface roughness and reactive elements doping is negligible, due to the polishing and same doping of reactive element $\mathrm{Y}$ before oxidation. It has been reported that the refinement of grain size to nanoscale can facilitate the earlier establishment of $\alpha-\mathrm{Al}_{2} \mathrm{O}_{3}$, which is induced by the significantly increased grain boundary density [53, 54]. The $\mathrm{NiCoCrAlY}$ coating typically comprises of $\gamma$-Ni and $\beta$-NiAl phases. The $\beta$ phase is rich in $\mathrm{Al}$ and thereby favors the formation of $\alpha-\mathrm{Al}_{2} \mathrm{O}_{3}$ scale. Thus the exclusive nucleation and formation of $\alpha-\mathrm{Al}_{2} \mathrm{O}_{3}$ scale will be controlled by the oxidation of the $\gamma$-phase. It has been reported by Chen et.al [5] that the nano-sized $\gamma$-grains $(<700 \mathrm{~nm})$ in the HVOFsprayed NiCoCrAlY coating can promote the formation of exclusive $\alpha-\mathrm{Al}_{2} \mathrm{O}_{3}$. In addition, the $\gamma$-grain with an elongated shape is also beneficial to the formation of exclusive $\alpha-\mathrm{Al}_{2} \mathrm{O}_{3}[5]$. As presented in Fig. 2 and 3, the grain size of elongated $\gamma$-grains in the HVAF coating is about $500 \mathrm{~nm}(<700 \mathrm{~nm})$. For the HVAF-V and HVAF-S coatings, the $\gamma$-grains coarsen to order of magnitudes of several micrometers and almost become equiaxed. On the other hand, it is also reported that the formation of dislocations in the HVOF coating can increase the number of nucleation sites of $\alpha$ $\mathrm{Al}_{2} \mathrm{O}_{3}[5,55]$. The spray particles in a plastic state rather than in a melted state strike onto substrate, due to the extremely high velocity and relatively low temperature in the HVOF spraying [56]. Thus the dislocations come from the "cold deformation" upon 
impact with the substrate. Fig. 17 shows a bright-field TEM image (Fig. 17a) of the HVAF coating and the corresponding diffraction pattern (Fig. 17b) of a $\beta$-grain. It can be clearly seen that the diffraction spots are elongated and diffuse, which is attributed to the distortions of the lattice associated with the presence of the large number of the dislocations. Thus the dislocations are also present in NiCoCrAlY coating fabricated by HVAF which uses lower deposition temperatures and involves more cold deformation of the particles than HVOF [16]. Based on the analysis above, the fastest phase transformation rate of $\theta-\mathrm{Al}_{2} \mathrm{O}_{3}$ to $\alpha-\mathrm{Al}_{2} \mathrm{O}_{3}$ for the HVAF coating can be attributed to the fine grain sizes (Fig. 2 and 3) and more dislocations (Fig. 17). Both HVAF-V coating $\left(1100{ }^{\circ} \mathrm{C}, 4 \mathrm{~h}\right)$ and HVAF-S coating $\left(1050{ }^{\circ} \mathrm{C}, 10 \mathrm{~min}, 50 \mathrm{MPa}\right)$ are heat treated. For the HVAF-V coating, the dislocations may disappear due to the high heat treatment temperature and long time. However, for the HVAF-S coating, it is likely that the dislocations are not completely disappear due to the fast sintering capacity of SPS technique (relatively lower temperature and shorter time). Since the grain sizes are basically equal for the HVAF-V and HVAF-S coatings (Fig. 4), the faster phase transformation rate of $\theta-\mathrm{Al}_{2} \mathrm{O}_{3}$ to $\alpha-\mathrm{Al}_{2} \mathrm{O}_{3}$ may be induced by the remaining dislocations in the HVAF-S coating in comparison to the HVAF-V coating.
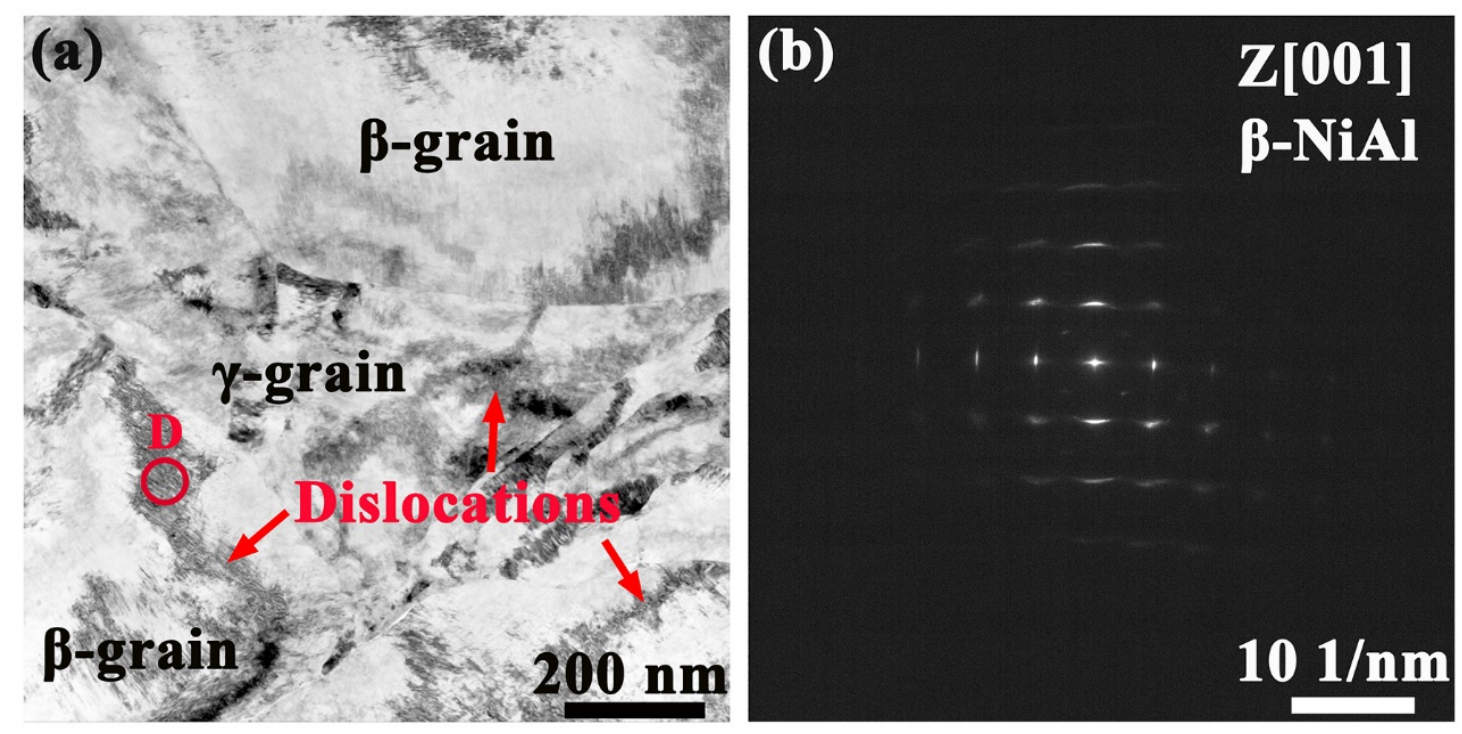

Fig. 17. TEM analysis of the HVAF coating: (a) bright-field image, showing the presence of the larger number of dislocations and (b) diffraction pattern of the $\beta$-grain marked with "D" in Fig. 17a. The diffraction spots are elongated and diffuse. 


\subsection{Effect of coating microstructure on TGO growth rate}

As presented in Section 3.4, the HVAF-S coating shows the lowest TGO thickness after $25 \mathrm{~h}$ oxidation. However, up to an oxidation time of $25 \mathrm{~h}$, the HVAF coating exhibits the lowest TGO thickness. In addition, the TGO thickness for HVAF-V coating is always maximal for the whole oxidation stage. In the present work, the growth of TGO is primarily affected by the transformation rate of alumina and the porosity (pores). The contribution of $\theta-\mathrm{Al}_{2} \mathrm{O}_{3}$ content in $\mathrm{Al}_{2} \mathrm{O}_{3}$ scale to overall TGO thickness cannot be neglected, due to about an order of magnitude higher growth rate of $\theta-\mathrm{Al}_{2} \mathrm{O}_{3}$ than $\alpha$ $\mathrm{Al}_{2} \mathrm{O}_{3}[20,51]$. Moreover, the $\theta-\mathrm{Al}_{2} \mathrm{O}_{3}$ can favor the nucleation and growth of spinel, thereby further thickening the TGO, resulting from the porous microstructure of $\theta$ $\mathrm{Al}_{2} \mathrm{O}_{3}[5,57]$. Once the $\alpha-\mathrm{Al}_{2} \mathrm{O}_{3}$ scale is completely transformed, the pores in the coating will play a predominant role on the overall increase of TGO thickness. First, the localized insufficient aluminum supply from the coating leads to the formation of spinel around the pores, due to the increased infiltration paths for the diffusion of other metal elements (Fig. 10b and e)[7]. It is also reported by Evans and Taylor [9] that the internally formed oxides in the coatings provide the diffusion barriers preventing the supply of aluminum from the coatings, resulting in the formation of spinel and breakaway oxides. Then the spinel and breakaway oxides grows at an intrinsically much higher rate than the protective $\alpha-\mathrm{Al}_{2} \mathrm{O}_{3}$, which further thicken the TGO [7, 9-11]. For instance, the parabolic rate constant for $\mathrm{NiO}$ scale growing in air at $1100{ }^{\circ} \mathrm{C}$ is typically three orders of magnitude higher than that of the protective $\alpha-\mathrm{Al}_{2} \mathrm{O}_{3}$ [41]. For the HVAF-V coating, the relatively high temperature and long time during the vacuum heat treatment might lead to the formation of nano-sized alumina scale surrounding the unmelted particle boundaries. Then this alumina scale hinders the diffusion of aliminum from the unmelted particle and thereby causes severely internal oxidation around the unmelted particle boundaries (Fig. 10d and e). Therefore, the higher TGO growth rate for the HVAF-V coating can be attributed to the higher $\theta-\mathrm{Al}_{2} \mathrm{O}_{3}$ content in $\mathrm{Al}_{2} \mathrm{O}_{3}$ scale and severe internal oxidation, in comparison to other two types of coatings (Fig. 10 and 13). Two important features in Fig. 12 should be noted. First, the TGO thickness for the 
HVAF coating is lower compared with the HVAF-S coating by the first $25 \mathrm{~h}$. This result primarily comes from the contribution of the lower $\theta-\mathrm{Al}_{2} \mathrm{O}_{3}$ content in $\mathrm{Al}_{2} \mathrm{O}_{3}$ scale for the HVAF coating. Second, the difference in TGO thickness is constantly reduced between HVAF and HVAF-S coatings up to an oxidation time of $25 \mathrm{~h}$. Furthermore, the TGO thickness for HVAF coating exceeds that of HVAF-S coating after $25 \mathrm{~h}$ oxidation. The Al concentration is sufficient to nucleate alumina in the early stage for the HVAF coating. However, the aluminum concentration in the HVAF coating declines quickly due to the continuous TGO growth and severe internal oxidation (Fig. 10a and b). Then the spinel forms in the Al-depletion zones, which results in the fast TGO growth (Fig $10 \mathrm{~b}$ and $\mathrm{c})$. For the HVAF-S coating, a higher $\theta-\mathrm{Al} 2 \mathrm{O} 3$ content in $\mathrm{Al}_{2} \mathrm{O}_{3}$ scale leads to a higher TGO thickness in the early oxidation stage compared with the HVAF coating, but the HVAF-S coating shows the lowest TGO growth rate for the long-term oxidation due to the dense microstructure of coating. In other words, the porosity plays a predominant role on the oxidation resistance rather than grain size for the long-term oxidation.

\subsection{Effect of coating microstructure on residual stress in TGO}

Fig. 15 shows the residual stress in TGO for the HVAF-S coating remains stable $(\sim 4.5$ GPa) for the long-term oxidation. However, for the HVAF and HVAF-V coatings, the residual stress in TGO keeps constant decline until the failure of TGO. As presented in Fig. 10, the severe internal oxidation is found at the TGO/coating interface for HVAF and HVAF-V coatings. The localized volume expansion at interface due to severe internal oxidation easily leads to the stress concentration and thereby initiates the interfacial cracks [48]. The formation of interfacial cracks can release the residual stress in TGO. Thus the continuous decrease in the residual stress with the oxidation time for HVAF and HVAF-V coatings could be attributed to the nucleation and propagation of interfacial cracks. The faster decrease in the TGO residual stress for HVAF-V coating in comparison to HVAF coating could be attributed to more severe interface separation. It is clearly presented in Fig. 16 that the stress relaxation always occurs surrounding the 
spinel, which causes a non-uniform and unstable stress distribution in TGO. As discussed in Section 4.2, the spinel is brittle and fast growing [7]. Localized volume expansion in TGO induced by the fast growth of spinel introduce significant stress concentration, which makes TGO fracture easily. Therefore, spallation of TGO initiates from these spinel zones, as indicated by micrographs in the Fig. 8 and 10. For the HVAF-S coating, the high, stable and uniformly distributed residual stress in TGO clearly indicates the mechanical stability of the TGO $[8,10]$, which can be supported by the good interface adhesion (Fig. 10) and superior spallation resistance of TGO (Fig. $6)$.

\subsection{Understanding the TGO Spallation}

Based on the discussion above, different spallation patterns can be found for three types of coatings. For the HVAF and HVAF-V coatings, the spallation of TGO first initiates from the spinel zones and subsequently spreads all over the surface of coatings upon cooling with the increased oxidation time (Fig. 8 and 10). For the HVAF coating, only minor quantity of detachment of TGO occurs after $100 \mathrm{~h}$ oxidation. Therefore, the following section devotes to discuss the failure behavior for all coatings.

It is well documented that two competing failure mechanisms consisting of edge and buckling driven delamination interact for a compressed film system $[48,58]$. When films subject to an equi-biaxial compressive stress state, the elastic strain energy stored in TGO. The associated energy release rate $G$ in the TGO is expressed as [48, 59]:

$$
G=\frac{1-v_{\mathrm{ox}}^{2}}{2 E_{\mathrm{ox}}} \sigma^{2} h_{o x}
$$

where $\sigma, h_{o x}, E_{o x}$, and $v_{o x}$ are the residual stress, thickness, Young's modulus and Poisson's ration of the TGO layer, respectively.

Assuming the coating fails by edge driven delamination. The size of interfacial cracks to initiate an edge delamination is generally on the order of several TGO thicknesses. For a film system in compression, the interfacial crack belongs to model II[48]. Under the idealized assumption that frictional sliding plays a negligible role on the 
consumption of energy stored in TGO. Therefore, when the energy release rate $G$ exceeds the interfacial toughness of mode II $\Gamma_{i}^{\mathrm{II}}$, the critical TGO thickness for the edge delamination without arrest is[48, 58, 59]:

$$
h_{o x}^{c}=\frac{2 E_{\mathrm{ox}} \Gamma_{\mathrm{i}}^{\mathrm{II}}}{\left(1-v_{\mathrm{ox}}^{2}\right) \sigma^{2}}
$$

with $E_{o x}=380 \mathrm{GPa}[60], \quad v_{o x}=0.25[60], \quad \sigma=4.5 \mathrm{GPa}\left(\right.$ Fig. 14) and $\Gamma_{\mathrm{i}}^{\mathrm{II}}=80 \mathrm{~J} / \mathrm{m}^{2}[61]$, the estimated critical TGO thickness is about $3.2 \mu \mathrm{m}$.

If the coating fails by buckling driven delamination, buckling delamination occurs when length of pre-existing interfacial crack exceeds the critical width of detached film $d_{\mathrm{c}}[48,62]$ :

$$
d_{\mathrm{c}}=\sqrt{\frac{\pi^{2} E_{\mathrm{ox}} h_{o x}{ }^{2}}{3\left(1-v_{\mathrm{ox}}{ }^{2}\right) \sigma}}
$$

The estimated critical width of detached TGO is about 17 times of TGO thickness.

Based on the above analysis for the failure mechanisms of TGO, the edge delamination plays a predominant role on the TGO failure when TGO thickness exceeds the critical thickness. For the HVAF coating, the detachment of TGO first occurs in the weak area where spinel forms, as shown in Fig. 8 and 10. Then the detached area creates new edge for edge delamination. Thus the TGO suffer severe spallation (oxidation for $100 \mathrm{~h}$ ) (Fig. 6), while TGO thickness exceeds the critical thickness $(3.2 \mu \mathrm{m})$. This result is quite well consistent with the estimated critical thickness, which is presented in Fig. 12. When the TGO thickness is lower than critical thickness, the localized spallation of TGO occurs around the spinel (oxidation for 50 h) (Fig. 8). For HVAF-V coating, the amount of spinel in TGO is lower in comparison to HVAF coating (Fig. 9), but the TGO thickness exceeds the critical thickness in the earlier time (oxidation for $50 \mathrm{~h}$ ) (Fig. 12). At this moment, the significant spallation of TGO starts to occur (Fig. 6). These results indicates that once the new edge is created and the TGO thickness exceeds the critical thickness, the edge driven failure of TGO will lead to severe TGO spallation. Therefore, the HVAF-V coating shows a much higher spallation degree of TGO after oxidation for $50 \mathrm{~h}(\sim 31 \%)$, compared with the HVAF coating ( $\sim 10 \%)$. For the HVAF-S coating, the 
TGO suggests a buckling delamination mode of failure due to the growth of uniform TGO and good interface adhesion (Fig. 10h and i). The calculated critical width of detached area by equation (5) is about $59.9 \mu \mathrm{m}$ in a $3.5 \mu \mathrm{m}$ thick TGO (oxidation for $100 \mathrm{~h})$. This width is very close to minimum width of the spalled area $(50 \sim 120 \mu \mathrm{m})$ observed in Fig. 10g. In other words, the detachment of TGO occurs, only when the length of pre-existing interfacial crack exceeds $59.9 \mu \mathrm{m}$ (17 times of TGO thickness). Since the interface pore is only microstructural imperfection at the spalled interface (Fig. 10g), the pore might be the nucleation site of initial interfacial crack. However, the pore is hardly detected away from the spalled area (Fig. 10h). Thus the nucleation and propagation interfacial crack are well suppressed by the good interface adhesion and low TGO growth rate for the HVAF-S coating.

In general, the superior spallation resistance of TGO for the HVAF-S coating can be attributed to the uniform, continuous and slowly growing TGO layer and good interface adhesion, which result from the fully dense and uniform microstructure of coating.

\section{Conclusions}

In this study, the effect of grain size, dislocations and porosity of a NiCoCrAlY coating fabricated by high-velocity air fuel (HVAF) on the isothermal oxidation behavior is systematically investigated and compared with those fabricated by HVAF coating after vacuum heat treatment (HVAF-V) and HVAF coating after spark plasma sintering (SPS) treatment (HVAF-S). The following conclusions can be drawn:

1. The intrinsic defects in the as-sprayed HVAF coating are the pores without internal oxides, which involve extremely low deposition temperature and high flight velocity of particle. The porosity in the HVAF coating is estimated to be $3.58 \%$. For the HVAF-V coating, the porosity is reduced to $\sim 1.96 \%$. However, the pores at the unmelted particle boundary cannot be completely eliminated after vacuum heat treatment. The HVAF-S coating shows a fully dense microstructure with a porosity of $\sim 0.16 \%$, which can be attributed to the capability of fast sintering of SPS.

2. The fine grain size of $\gamma$-grains and dislocations in the HVAF coating can facilitate 
the earlier establishment of $\alpha-\mathrm{Al}_{2} \mathrm{O}_{3}$ in the early time, which is beneficial to lowering the TGO growth rate. For the HVAF-V and HVAF-S coatings, the transformation rate of $\theta-\mathrm{Al}_{2} \mathrm{O}_{3}$ to $\alpha-\mathrm{Al}_{2} \mathrm{O}_{3}$ is lowered due to the grain growth and dislocations recovery.

3. The porosity plays a predominant role on the TGO growth rate for the long-term oxidation. Additionally, the contribution of grain size and dislocations in the coatings to the TGO growth rate can be counteracted by that of porosity with the increased oxidation time.

4. The formation of spinel in the TGO and severe internal oxidation can be observed for the HVAF and HVAF-V coatings due to the relatively high porosity. However, the TGO predominantly consists of alumina and no internal oxidation is found for the HVAF-S coating, which benefit from the fully dense microstructure.

5. The isothermal oxidation tests at $1150{ }^{\circ} \mathrm{C}$ demonstrate that the HVAF-S coating shows a much better oxidation and spallation resistance of TGO, compared with the HVAF and HVAF-V coatings. The spinel and internal oxidation are detrimental to the stability of TGO.

6. The stability and uniformity of residual stress in TGO for the HVAF-S coating for the long-term oxidation indicates a good interface adhesion between TGO and coating. The constantly decrease in the residual stress in TGO with the oxidation time for HVAF and HVAF-V coatings manifest a weak interface adhesion. Furthermore, the distribution of residual stress around the spinel shows that the stress relaxation prefers to occur in this zone by the nucleation and propagation of cracks.

In summary, vacuum heat treatment cannot completely eliminate the pores at the unmelted particle boundaries in the HVAF coating and instead increases the grain size. Thus the internal oxidation is still inevitable after thermal exposure. Additionally, the increased grain size will delay the transformation of $\theta-\mathrm{Al}_{2} \mathrm{O}_{3}$ to $\alpha-\mathrm{Al}_{2} \mathrm{O}_{3}$. The spark plasma sintering is a promising method to fully densify the microstructure of coating with a low oxygen content (e.g. HVAF). Perhaps the porosity of HVAF coating can be reduced by regulating the spray parameter and size distribution of spray particles. 


\section{Acknowledgements}

This work was supported by the Inner Mongolia Natural Science Foundation (No. 2017MS0538) and Baotou-SJTU innovation funding.

\section{References}

[1] N.P. Padture, M. Gell, E.H. Jordan, Thermal barrier coatings for gas-turbine engine applications, Science, 296 (2002) 280-284.

[2] A.G. Evans, D.R. Mumm, J.W. Hutchinson, G.H. Meier, F.S. Pettit, Mechanisms controlling the durability of thermal barrier coatings, Progress in Materials Science, 46 (2001) 505-553.

[3] G.W. Goward, Progress in coatings for gas turbine airfoils, Surface and Coatings Technology, 108-109 (1998) 73-79.

[4] J.T. DeMasi-Marcin, D.K. Gupta, Protective coatings in the gas turbine engine, Surface and Coatings Technology, 68-69 (1994) 1-9.

[5] Y. Chen, X. Zhao, P. Xiao, Effect of microstructure on early oxidation of MCrAlY coatings, Acta Materialia, 159 (2018) 150-162.

[6] L. Luo, X. Shan, Z. Zou, C. Zhao, X. Wang, A. Zhang, X. Zhao, F. Guo, P. Xiao, A high performance NiCoCrAlY bond coat manufactured using laser powder deposition, Corrosion Science, 126 (2017) 356-365.

[7] Y. Li, C.-J. Li, G.-J. Yang, L.-K. Xing, Thermal fatigue behavior of thermal barrier coatings with the MCrAlY bond coats by cold spraying and low-pressure plasma spraying, Surface and Coatings Technology, 205 (2010) 2225-2233.

[8] E.P. Busso, H.E. Evans, Z.Q. Qian, M.P. Taylor, Effects of breakaway oxidation on local stresses in thermal barrier coatings, Acta Materialia, 58 (2010) 1242-1251.

[9] H.E. Evans, M.P. Taylor, Diffusion Cells and Chemical Failure of MCrAlY Bond Coats in Thermal-Barrier Coating Systems, Oxidation of Metals, 55 (2001) 17-34. [10] V.K. Tolpygo, D.R. Clarke, K.S. Murphy, Oxidation-induced failure of EB-PVD thermal barrier coatings, Surface and Coatings Technology, 146-147 (2001) 124-131. 
[11] P. Niranatlumpong, C.B. Ponton, H.E. Evans, The Failure of Protective Oxides on Plasma-Sprayed NiCrAlY Overlay Coatings, Oxidation of Metals, 53 (2000) 241-258. [12] Y. Han, Z. Zhu, B. Zhang, Y. Chu, Y. Zhang, J. Fan, Effects of process parameters of vacuum pre-oxidation on the microstructural evolution of CoCrAlY coating deposited by HVOF, Journal of Alloys and Compounds, 735 (2018) 547-559.

[13] W. Brandl, G. Marginean, D. Maghet, D. Utu, Effects of specimen treatment and surface preparation on the isothermal oxidation behaviour of the HVOF-sprayed MCrAlY coatings, Surface and Coatings Technology, 188-189 (2004) 20-26.

[14] W. Brandl, D. Toma, H.J. Grabke, The characteristics of alumina scales formed on HVOF-sprayed MCrAlY coatings, Surface and Coatings Technology, 108-109 (1998) 10-15.

[15] E. Sadeghimeresht, N. Markocsan, P. Nylén, Microstructural characteristics and corrosion behavior of HVAF- and HVOF-sprayed Fe-based coatings, Surface and Coatings Technology, 318 (2017) 365-373.

[16] R.Q. Guo, C. Zhang, Q. Chen, Y. Yang, N. Li, L. Liu, Study of structure and corrosion resistance of Fe-based amorphous coatings prepared by HVAF and HVOF, Corrosion Science, 53 (2011) 2351-2356.

[17] E. Sadeghimeresht, N. Markocsan, P. Nylén, Microstructural and electrochemical characterization of Ni-based bi-layer coatings produced by the HVAF process, Surface and Coatings Technology, 304 (2016) 606-619.

[18] P. Zhang, E. Sadeghimeresht, S. Chen, X.-H. Li, N. Markocsan, S. Joshi, W. Chen, I.A. Buyanova, R.L. Peng, Effects of surface finish on the initial oxidation of HVAFsprayed NiCoCrAlY coatings, Surface and Coatings Technology, 364 (2019) 43-56.

[19] T. Sui, B. Song, J. Dluhos, L. Lu, A.M. Korsunsky, Nanoscale chemical mapping of Li-ion battery cathode material by FIB-SEM and TOF-SIMS multi-modal microscopy, Nano Energy, 17 (2015) 254-260.

[20] C. Zhao, Y. Zhou, Z. Zou, L. Luo, X. Zhao, F. Guo, P. Xiao, Effect of alloyed Lu, $\mathrm{Hf}$ and $\mathrm{Cr}$ on the oxidation and spallation behavior of NiAl, Corrosion Science, 126 (2017) 334-343.

[21] T.J. Nijdam, W.G. Sloof, Effect of Y Distribution on the Oxidation Kinetics of 
NiCoCrAlY Bond Coat Alloys, Oxidation of Metals, 69 (2007) 1-12.

[22] J. Lu, Y. Chen, C. Zhao, H. Zhang, L. Luo, B. Xu, X. Zhao, F. Guo, P. Xiao, Significantly improving the oxidation and spallation resistance of a MCrAlY alloy by controlling the distribution of yttrium, Corrosion Science, 153 (2019) 178-190.

[23] J. Shi, H.Q. Li, M.Q. Wan, H.L. Wang, X. Wang, High temperature oxidation and inter-diffusion behavior of electroplated $\mathrm{Ni}-\mathrm{Re}$ diffusion barriers between NiCoCrAlY coating and orthorhombic-Ti 2 AlNb alloy, Corrosion Science, 102 (2016) 200-208.

[24] O. Knotek, E. Lugscheider, F. Löffler, W. Beele, Diffusion barrier coatings with active bonding, designed for gas turbine blades, Surface and Coatings Technology, 6869 (1994) 22-26.

[25] H. Peng, H. Guo, J. He, S. Gong, Cyclic oxidation and diffusion barrier behaviors of oxides dispersed NiCoCrAlY coatings, Journal of Alloys and Compounds, 502 (2010) 411-416.

[26] S. Deshpande, A. Kulkarni, S. Sampath, H. Herman, Application of image analysis for characterization of porosity in thermal spray coatings and correlation with small angle neutron scattering, Surface and Coatings Technology, 187 (2004) 6-16.

[27] K.P. Trumble, M. Rühle, The thermodynamics of spinel interphase formation at diffusion-bonded Ni/A12O3 interfaces, Acta Metallurgica et Materialia, 39 (1991) 1915-1924.

[28] R.G. Wellman, A. Scrivani, G. Rizzi, A. Weisenburger, F.H. Tenailleau, J.R. Nicholls, Pulsed electron beam treatment of MCrAlY bondcoats for EB PVD TBC systems part 2 of 2: Cyclic oxidation of the coatings, Surface and Coatings Technology, 202 (2007) 709-713.

[29] E.A.G. Shillington, D.R. Clarke, Spalling failure of a thermal barrier coating associated with aluminum depletion in the bond-coat, Acta Materialia, 47 (1999) 12971305.

[30] B.A. Pint, Optimization of Reactive-Element Additions to Improve Oxidation Performance of Alumina-Forming Alloys, Journal of the American Ceramic Society, 86 (2003) 686-695.

[31] J.A. Nychka, D.R. Clarke, Quantification of Aluminum Outward Diffusion During 
Oxidation of FeCrAl Alloys, Oxidation of Metals, 63 (2005) 325-352.

[32] D. Naumenko, B.A. Pint, W.J. Quadakkers, Current Thoughts on Reactive Element Effects in Alumina-Forming Systems: In Memory of John Stringer, Oxidation of Metals, $86(2016) 1-43$.

[33] A. Kumar, M. Nasrallah, D.L. Douglass, The effect of yttrium and thorium on the oxidation behavior of Ni-Cr-Al alloys, Oxidation of Metals, 8 (1974) 227-263.

[34] D. Li, H. Guo, D. Wang, T. Zhang, S. Gong, H. Xu, Cyclic oxidation of $\beta$-NiAl with various reactive element dopants at $1200^{\circ} \mathrm{C}$, Corrosion Science, 66 (2013) 125135.

[35] B.A. Pint, M. Treska, L.W. Hobbs, The effect of various oxide dispersions on the phase composition and morphology of $\mathrm{Al} 2 \mathrm{O} 3$ scales grown on $\beta$-NiAl, Oxidation of Metals, 47 (1997) 1-20.

[36] F.A. Golightly, F.H. Stott, G.C. Wood, The influence of yttrium additions on the oxide-scale adhesion to an iron-chromium-aluminum alloy, Oxidation of Metals, 10 (1976) 163-187.

[37] D.G. Lees, On the reasons for the effects of dispersions of stable oxides and additions of reactive elements on the adhesion and growth-mechanisms of chromia and alumina scales-the ?sulfur effect?, Oxidation of Metals, 27 (1987) 75-81.

[38] X. Wang, G. Lee, A. Atkinson, Investigation of TBCs on turbine blades by photoluminescence piezospectroscopy, Acta Materialia, 57 (2009) 182-195.

[39] B. Pint, The oxidation mechanism of $\theta-A 12 O 3$ scales, Solid State Ionics, 78 (1995) 99-107.

[40] R.W. Jackson, D.M. Lipkin, T.M. Pollock, Thermal barrier coating adherence to Hf-modified B2 NiAl bond coatings, Acta Materialia, 80 (2014) 39-47.

[41] Y. Li, C.-J. Li, Q. Zhang, G.-J. Yang, C.-X. Li, Influence of TGO Composition on the Thermal Shock Lifetime of Thermal Barrier Coatings with Cold-sprayed MCrAlY Bond Coat, Journal of Thermal Spray Technology, 19 (2009) 168-177.

[42] V. Teixeira, M. Andritschky, W. Fischer, H.P. Buchkremer, D. Stöver, Effects of deposition temperature and thermal cycling on residual stress state in zirconia-based thermal barrier coatings, Surface and Coatings Technology, 120-121 (1999) 103-111. 
[43] L. Qiu, F. Yang, W. Zhang, X. Zhao, P. Xiao, Effect of Al content on the lifetime of thermally grown oxide formed on $\mathrm{Ni}-\mathrm{Al}$ alloys after isothermal oxidation, Corrosion Science, 89 (2014) 13-20.

[44] Y. Zhou, X. Zhao, C. Zhao, W. Hao, X. Wang, P. Xiao, The oxidation performance for Zr-doped nickel aluminide coating by composite electrodepositing and pack cementation, Corrosion Science, 123 (2017) 103-115.

[45] L. Yang, L. Zheng, H. Guo, The residual stress of oxide scales grown on Ni-Al alloys doped with minor Dy and Y, Corrosion Science, 112 (2016) 542-551.

[46] V.K. Tolpygo, D.R. Clarke, Alumina scale failure resulting from stress relaxation, Surface and Coatings Technology, 120-121 (1999) 1-7.

[47] Y. Chai, C. Lin, Y. Li, Effects of creep-plastic behavior on stress development in TBCs during cooling, Ceramics International, 43 (2017) 11627-11634.

[48] J.W. Hutchinson, M.Y. He, A.G. Evans, The influence of imperfections on the nucleation and propagation of buckling driven delaminations, Journal of the Mechanics and Physics of Solids, 48 (2000) 709-734.

[49] S.-S. Kim, Y.-F. Liu, Y. Kagawa, Evaluation of interfacial mechanical properties under shear loading in EB-PVD TBCs by the pushout method, Acta Materialia, 55 (2007) 3771-3781.

[50] N.M. Yanar, G.H. Meier, F.S. Pettit, The influence of platinum on the failure of EBPVD YSZ TBCs on NiCoCrAlY bond coats, Scripta Materialia, 46 (2002) 325-330. [51] V.K. Tolpygo, D.R. Clarke, Microstructural study of the theta-alpha transformation in alumina scales formed on nickel-aluminides, Materials at high temperatures 17 (2000) $59-70$.

[52] B.A. Pint, Limitations on the Use of Ion Implantation for the Study of the Reactive Element Effect in $\beta$-NiAl, Journal of The Electrochemical Society, 141 (1994) 2443.

[53] D. Mercier, B.D. Gauntt, M. Brochu, Thermal stability and oxidation behavior of nanostructured NiCoCrAlY coatings, Surface and Coatings Technology, 205 (2011) 4162-4168.

[54] Q. Zhang, C.-J. Li, C.-X. Li, G.-J. Yang, S.-C. Lui, Study of oxidation behavior of nanostructured NiCrAlY bond coatings deposited by cold spraying, Surface and 
Coatings Technology, 202 (2008) 3378-3384.

[55] D. Salehi Doolabi, M.R. Rahimipour, M. Alizadeh, S. Pouladi, S.M.M. Hadavi, M.R. Vaezi, Effect of high vacuum heat treatment on microstructure and cyclic oxidation resistance of HVOF-CoNiCrAlY coatings, Vacuum, 135 (2017) 22-33.

[56] E. Lugscheider, C. Herbst, L. Zhao, Parameter studies on high-velocity oxy-fuel spraying of MCrAlY coatings, Surface and Coatings Technology, 108-109 (1998) 1623.

[57] C. Kaplin, M. Brochu, Effects of water vapor on high temperature oxidation of cryomilled NiCoCrAlY coatings in air and low-SO2 environments, Surface and Coatings Technology, 205 (2011) 4221-4227.

[58] J.W. Hutchinson, Z. Suo, Mixed Mode Cracking in Layered Materials, Advances in Applied Mechanics, 29 (1991) 63-191.

[59] R.T. Wu, K. Kawagishi, H. Harada, R.C. Reed, The retention of thermal barrier coating systems on single-crystal superalloys: Effects of substrate composition, Acta Materialia, 56 (2008) 3622-3629.

[60] L.T. Wu, R.T. Wu, X. Zhao, P. Xiao, Microstructure parameters affecting interfacial adhesion of thermal barrier coatings by the EB-PVD method, Materials Science and Engineering: A, 594 (2014) 193-202.

[61] T. Xu, S. Faulhaber, C. Mercer, M. Maloney, A. Evans, Observations and analyses of failure mechanisms in thermal barrier systems with two phase bond coats based on NiCoCrAlY, Acta Materialia, 52 (2004) 1439-1450.

[62] F. Cao, B. Tryon, C.J. Torbet, T.M. Pollock, Microstructural evolution and failure characteristics of a NiCoCrAlY bond coat in "hot spot" cyclic oxidation, Acta Materialia, 57 (2009) 3885-3894. 